\title{
Deposition of $\mathrm{CaCO}_{3}$ in Porous Materials by Flashing Geothermal Fluid
}

Donald E. Michels REPUBLIC GEOTHERMAL, INC.

\section{迫eothermal RReservair 官ngineering นในลก 何ngram}

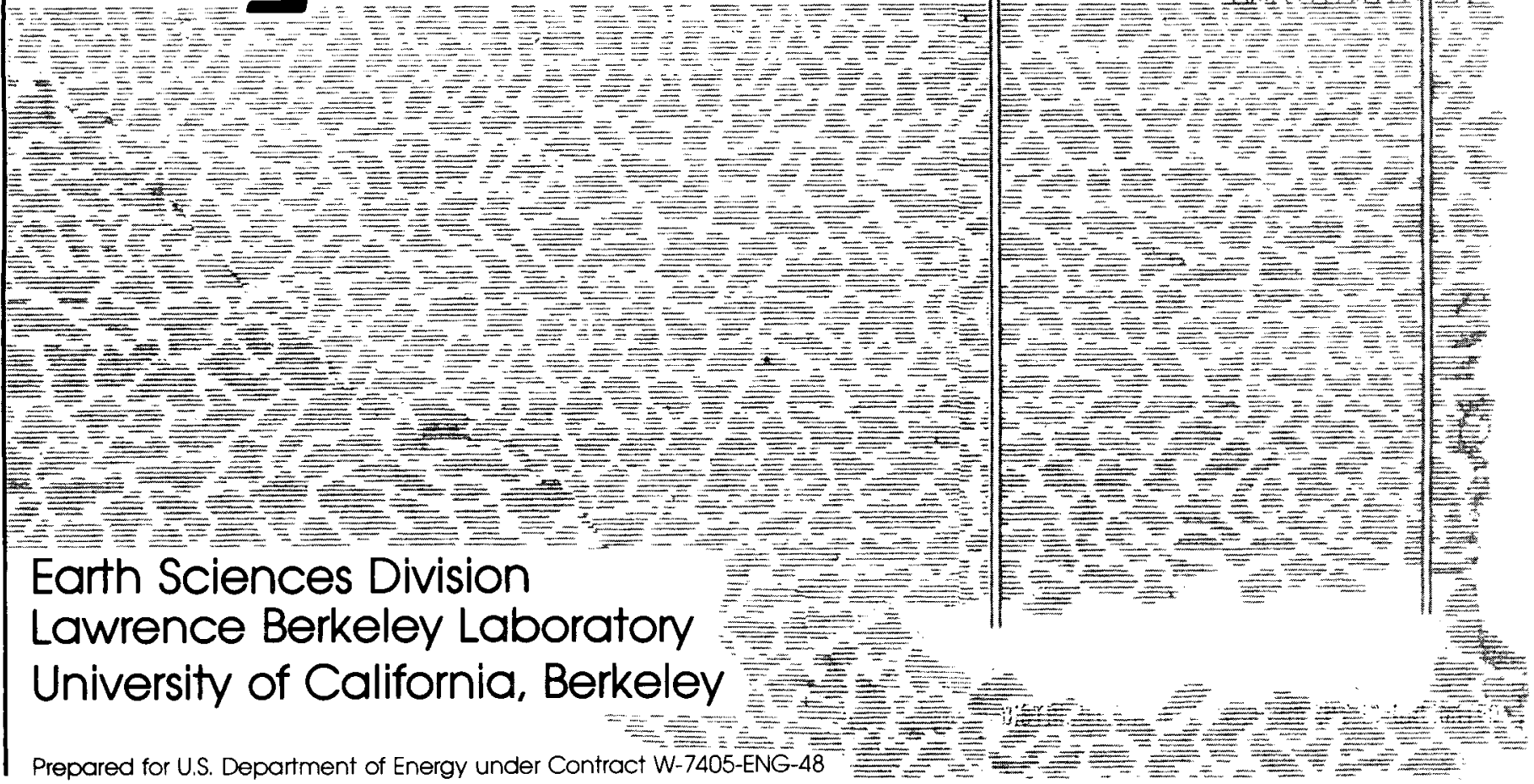




\section{DISCLAIMER}

This report was prepared as an account of work sponsored by an agency of the United States Government. Neither the United States Government nor any agency Thereof, nor any of their employees, makes any warranty, express or implied, or assumes any legal liability or responsibility for the accuracy, completeness, or usefulness of any information, apparatus, product, or process disclosed, or represents that its use would not infringe privately owned rights. Reference herein to any specific commercial product, process, or service by trade name, trademark, manufacturer, or otherwise does not necessarily constitute or imply its endorsement, recommendation, or favoring by the United States Government or any agency thereof. The views and opinions of authors expressed herein do not necessarily state or reflect those of the United States Government or any agency thereof. 


\section{DISCLAIMER}

Portions of this document may be illegible in electronic image products. Images are produced from the best available original document. 


\section{LEGAL NOTICE}

This book was prepared as an account of work sponsored by an agency of the United States Government. Neither the United States Government nor any agency thereof, nor any of their employees, makes any warranty, express or implied, or assumes any legal liability or responsibility for the accuracy, completeness, or usefulness of any information, apparatus, product, or process disclosed, or represents that its use would not infringe privately owned rights. Reference herein to any specific commercial product, process, or service by trade name, trademark, manufacturer, or otherwise, does not necessarily constitute or imply its endorsement, recommendation, or favoring by the United States Government or any agency thereof. The views and opinions of authors expressed herein do not necessarily state or reflect those of the United States Government or any agency thereof.

Printed in the United States of America

Available from

National Technical Information Service

U.S. Department of Commerce

5285 Port Royal Road

Springfield, VA 22161

Price Code: A0? 


\title{
DEPOSITION OF $\mathrm{CACO}_{3}$ IN POROUS MATERIALS BY FLASHING GEOTHERMAL FLUID \\ by \\ Donald E. Michels
}

\author{
Submitted to \\ LAWRENCE BERKELEY LABORATORY \\ as an \\ ACCOUNTING OF FIELD AND LABORATORY RESEARCH \\ under the \\ GEOTHERMAL RESERVOIR ENGINEERING MANAGEMENT PROGRAM \\ order \# 4555402
}

\author{
by \\ REPUBLIC GEOTHERMAL, INC. \\ 11823 E. S1auson Ave. \\ Santa Fe Springs, California 90670
}

This work was supported by the U.S. Department of Energy, Division of Geothermal Energy

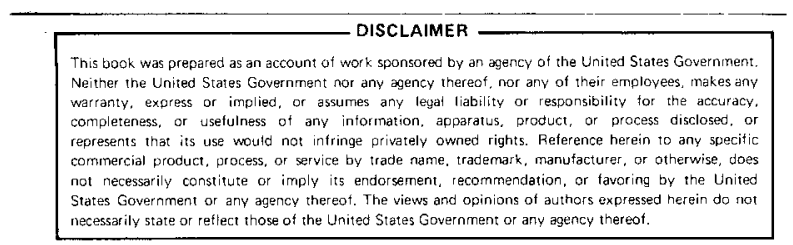


CONTENTS

Page No.

SUMMARY................................ 1

ACKNOWLEDGMENTS $\ldots \ldots \ldots \ldots \ldots \ldots \ldots \ldots \ldots \ldots \ldots \ldots \ldots \ldots \ldots$

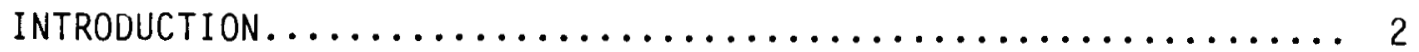

EXPERIMENTAL DESIGN

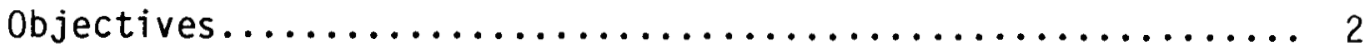

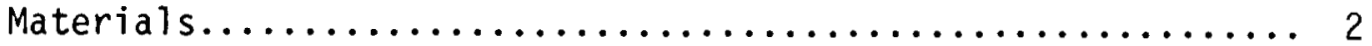

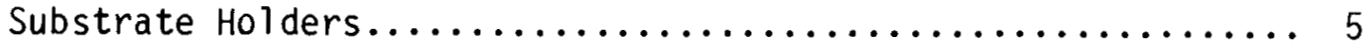

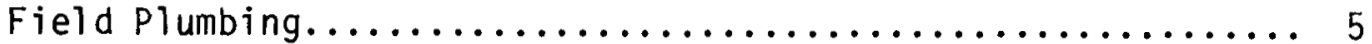

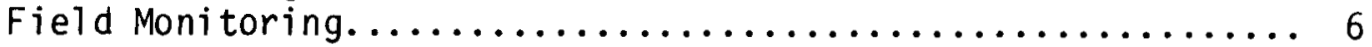

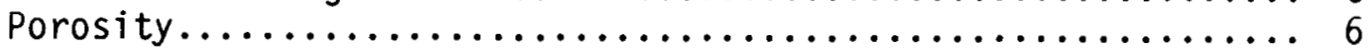

Residual Scale Components in Liquid Samples............. 7

RESULTS

Framework for Selecting Data...................... 8

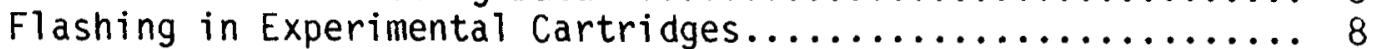

Fluid Transmissibilities.......................... 8 $\mathrm{CaCO}_{3}$ Deposition

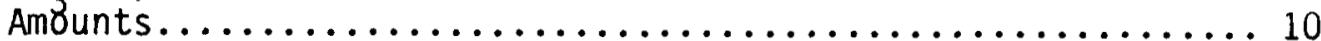

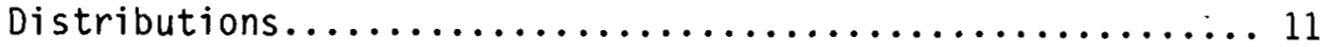

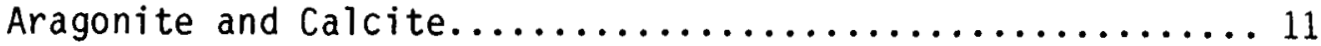

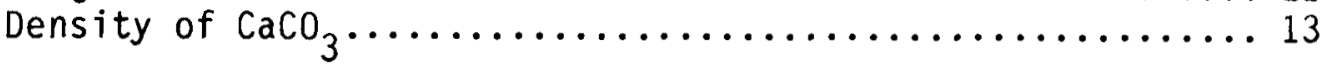

INTERPRETATION OF RESULTS

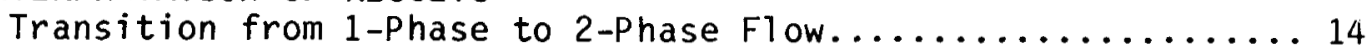

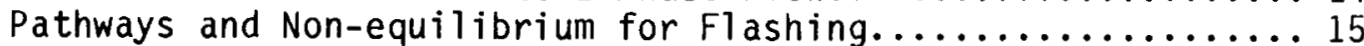

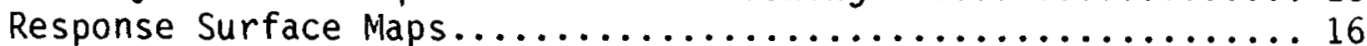

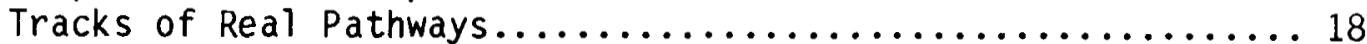

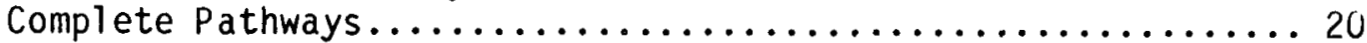

Implications About Crystal Growth Mechanisms.............. 21

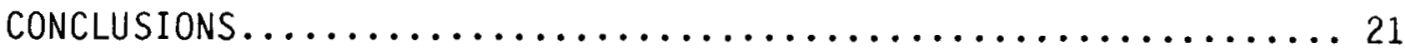

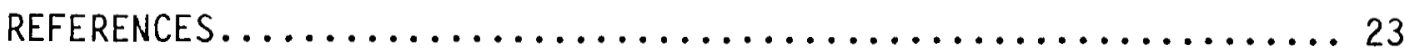

APPENDIX A

Mathmematical Basis for Response Surface Maps........... 23

APPENDIX B

Construction of Response Surface Maps................. 25

APPENDIX C

Equilibrium Paths Across Response Surfaces............. 27

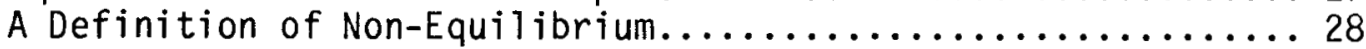




\section{DEPOSITION OF $\mathrm{CaCO}_{3}$ IN POROUS MATERIALS}

\section{BY FLASHING GEOTHERMAL FLUID}

Donald E. Michels

Republic Geothermal, Inc.

Santa Fe Springs, California

SUMMARY:

Deposition of $\mathrm{CaCO}_{3}$ from natural geothermal fluid was studied by using porous substrates made from several granular materials. These experiments aimed to explore connections between the process of steam flash from superheated $\mathrm{CO}_{2}$-charged water and the consequent changes in the carbonate chemical equilibria. The substrates were characterized pre- and postexperiment. Flow rates and compositions of input and output fluids were determined. The resultant $\mathrm{CaCO}_{3}$ deposits were examined from several points of view.

Results are presented in terms of processes which begin with the flashing of $\mathrm{CO}_{2}-\mathrm{H}_{2} \mathrm{O}$ from the liquid and affect the buildup of chemical potential to deposit $\mathrm{CaCO}_{3}$. Deposition is seen to $1 \mathrm{ag}$ the flashing, a feature deduced as due to delayed equilibration of $\mathrm{CO}_{2}$ between liquid and vapor phases. Both calcite and aragonite polymorphs of $\mathrm{CaCO}_{3}$ developed. Their contexts provide for deductions about the ionic events of crystal growth which are the scale deposition reactions.

Additional results show the nature of pore plugging of the substrates. Extrapolations to the context of natural rocks, receiving $\mathrm{CaCO}_{3}$ in the vicinity of a well bore, bear on strategies for rejuvenating plugged wells and on requirements for obtaining fluid from sensitive wells without damaging them.

Chemical factors that cause wells/fluids to be sensitive to $\mathrm{CaCO}_{3}$ deposition are highly correlated. Graphic methods for displaying the interplay of those factors are provided. The approach is general and applies also to pipes, valves, chambers, orifices, and other places wherein flashing is an essential part of the context. The described mechanisims by which the chemical potential for $\mathrm{CaCO}_{3}$ deposition responds to the flashing event are useful in seeking means of scale control.

The mechanical arrangements for the experiments are described in detail. Additional emphasis is given to the transition from 1 -phase to 2-phase flow as the 1 iquid begins to flash. Extended discussion is given on the buildup of the chemical potential for $\mathrm{CaCO}_{3}$ deposition.

The experimental context involved calcium concentrations in the liquid that were much less than bicarbonate concentrations. The results are less directly applicable to cases where calcium exceeds bicarbonate.

\section{ACKNOWLEDGMENTS}

Support for these studies comes from the Department of Energy, Division of Geothermal Eneray, through Lawrence Berkeley Laboratory under the Geothermal Reservoir Engineering Management Program, Order \# 4555402. Field facilities were provided by Repubtic Geothermal, Inc. at their East Mesa leasehold, Imperial Valley, California. The project was encouraged at all times by Werner Schwarz, Jack Howard, and 01 eh Weres of Lawrence Berkeley Laboratory, and by Robert Rex of Republic Geothermal, Inc. I am grateful to Don Campbe11 and Tom Strickland for their assistance in describing the hydrodynamic context of flashing, to Barry Monroe for the illustrations, and to Rhonda Carey, Trudy Fierros and Cindy Reece for the typescript. 


\section{INTRODUCTION:}

The deposition of $\mathrm{CaCO}_{3}$ has heen observed widely in qeothermal developments where superheated liquids flash to steam. Well bores are most seriously affected and similar deposition on uphole piping, valves, and steam separators adds an operational and economic burden to geothermal energy.

In some fields, geothermal wells tap steam, a feature which implies that conversion of 1 -phase liquid to a 2-phase system occurs remotely, yet within the pore spaces of reservoir rocks. Presumably, $\mathrm{CaCO}_{3}$ would deposit in these regions if components were available in the 1-phase liquid. Additionally, some proposed techniques of exploiting fields that are initially 1 -phase liquid will result in subsurface boiling so that the wells [will] come to produce steam instead of hot water (1). This method of exploitation carries the risk of damaging the rocks near the well bore by excessive deposition of $\mathrm{CaCO}_{3}$ in the porosity. Indeed, some test wells are suspected to have become non-productive due to such deposition (2). The problem is made more severe if the reservoir fluids are more rich in $\mathrm{CO}_{2}$ and if productivity of the rocks is inadequate to fill wellbores.

obtaining data on this phenomenon by observing $\mathrm{CaCO}_{3}$ deposition in a real geothermal reservoir is difficult due to complications of access, of chacterizing affected parts of the reservoir pre- and post-experiment, and of determining the relevant fluxes of fluids through the affected rocks. Accordingly, when a proposed pumping test of a geothermal well promised a reliable supply of fresh, overpressured, superheated geothermal water at a wellhead, it was proposed also to obtain a sidestream and allow that to flash in containers holding granular materials. Such porous matrices yield a surrogate reservoir in which to study deposition. Thus, in translating experimental results to reservoir conditions, validity of the chemical response can be presumed sound.

There is also an interdependence between fluid flash and chemical reactivity that has been little studied. The thermodynamic driving force for the chemical reactions of deposition builds from zero to substantial levels as the flashing progresses. In some ways, that build-up is accessible in this experiment and some emphasis will be given to its significance.

\section{EXPERIMENTAL DESIGN}

\section{Objectives}

The principal objective of this work is to examine mineral deposition that accompanies flashing in porous materials. Experimentally, there are several components to this study:

- select materials for substrates and characterize them

- design and fabricate hardware for holding the substrates

- arrange for water to flash in the porosity

- monitor flow rates and pressures
- make laboratory measurements of fluid transmissibilities

- make chemical analyses of liquid samples

- characterize the deposition re numerical data

- examine deposits in situ

- discuss results and observations

\section{Materials}

Nine granular materials and two rocks were used. The granular materials were selected to span a broad range of particle size, particle shape, and surface composition. Figure 1 shows the size ranges, plotted vs roundedness (3) for the free granular material, and suggests the wide range of particle packing characteristics explored in this study. All the natural materials were

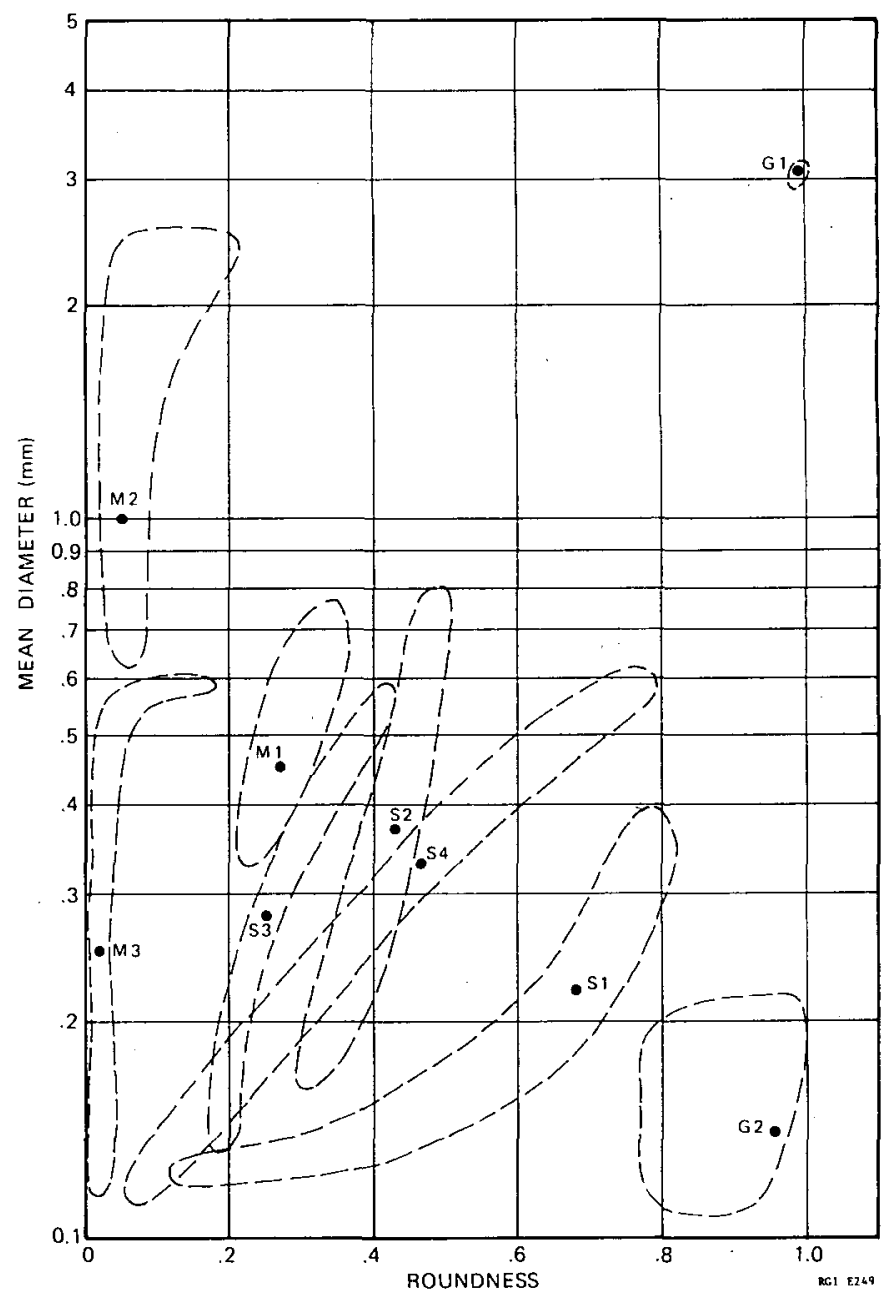

FIGURE 1: Ranges of size and shape for granular substrates.

washed with distilled water before using, in order to flush away fines, and dried at $140^{\circ} \mathrm{C}$. The metals and glass beads were degreased with trichlorethane before using. Photomicrographs of them are given as Fiqures $2 a$ through $2 j$. Three natural sands and drill cuttings provide a range of roundedness of grains. Spherical grains are provided by glass beads, two sizes of which were used. Three metal powders were used, 2 of which are highly irregular in shape and provide for porosities that are about twice that obtained with other materials. 


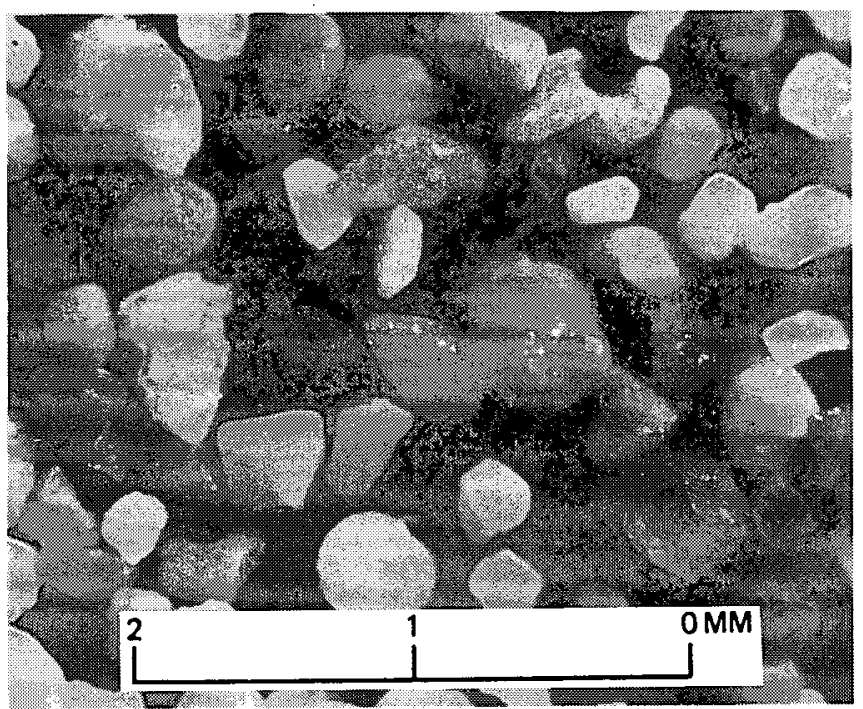

FIGURE 2a

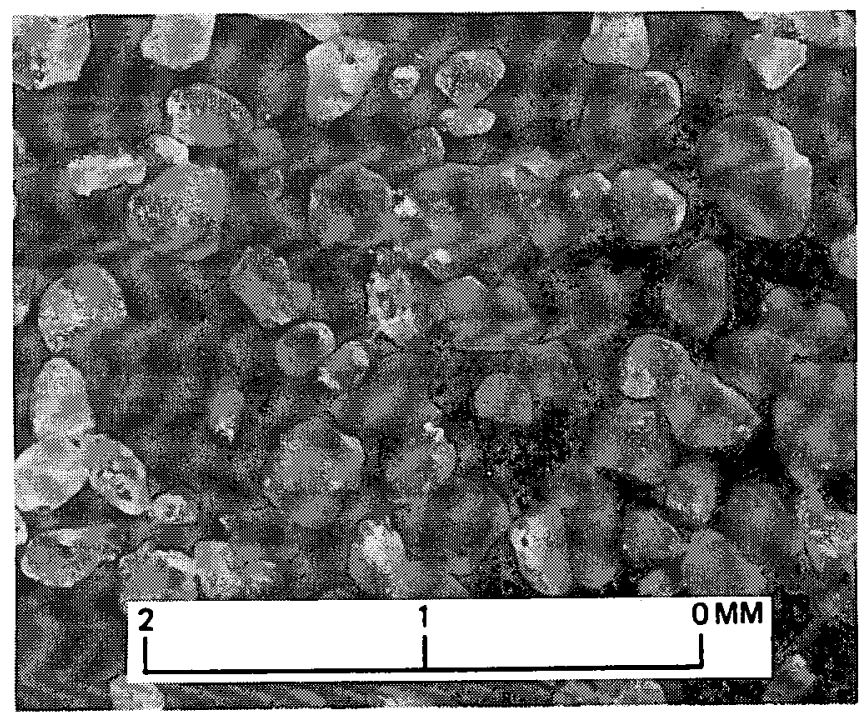

FIGURE 2c

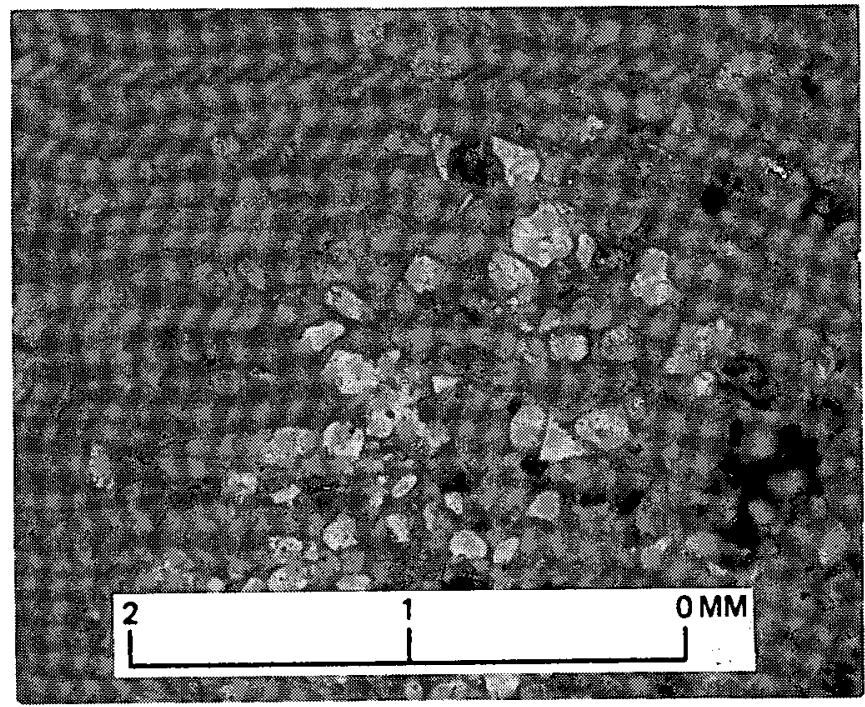

FIGURE $2 e$

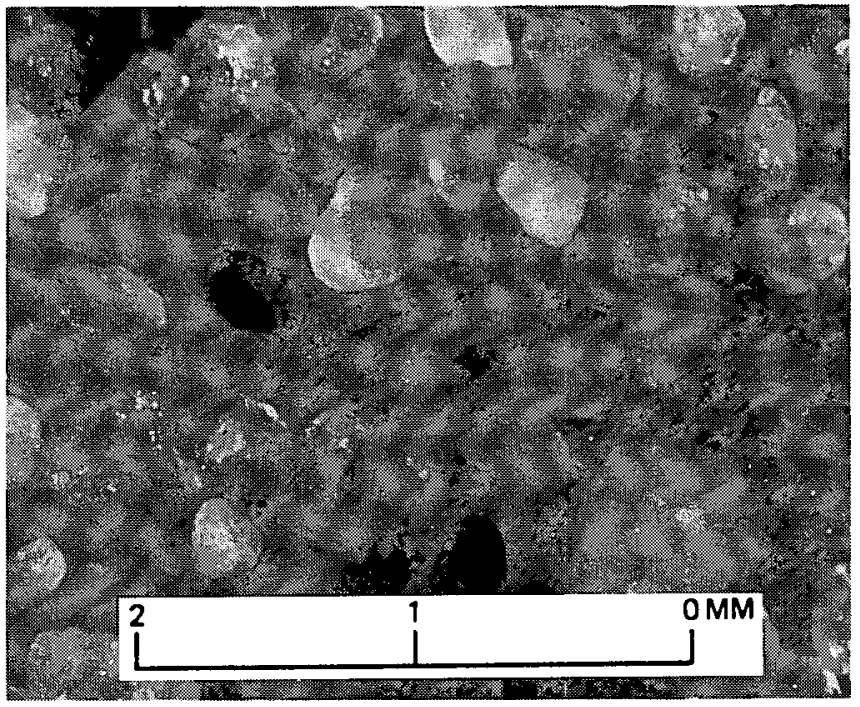

FIGURE 2b

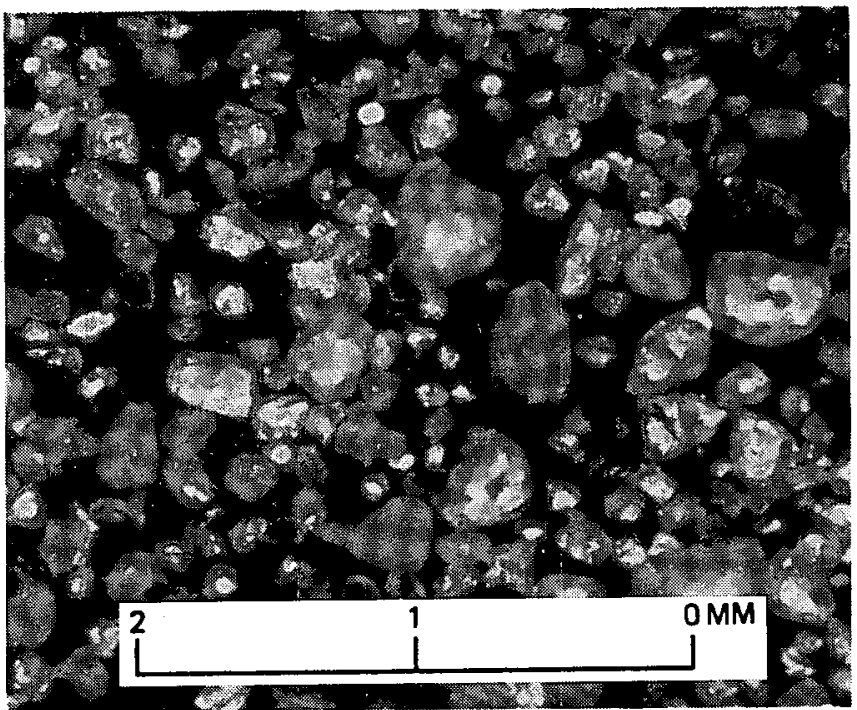

FIGURE 2d

FIGURE 2a: SAND 1, Calcareous beach sand from Kauai, Hawaii. Mostly sub-angular to round fragments of biotic shells. About $20 \%$ insoluble in 6MHC1, mainly apatite.

FIGURE 2b: SAND 2, Quartzose beach sand from Los Angeles, California, Free of $\mathrm{CaCO}_{3}$.

FIGURE 2c: SAND 3, Quartzose dune sand from East Mesa, Imperial County, California. Contains about $10 \% \mathrm{CaCO}_{3}$.

FIGURE 2d: SAND 4, Drill cuttings from a quartzose lacustrine sand (E.M. well 58-30). Clays and other fines have been removed by washing.

FIGURE 2e: ROCK 1: Thin section, quartzose lacustrine sand from a core, E.M. 78-30, $5500 \mathrm{ft}$. 


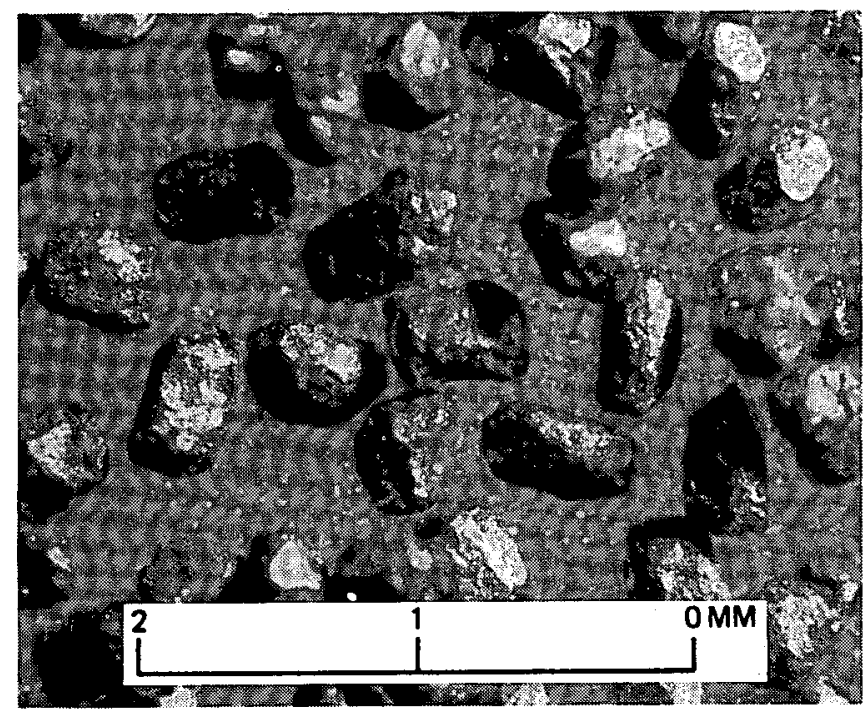

FIGURE 2f

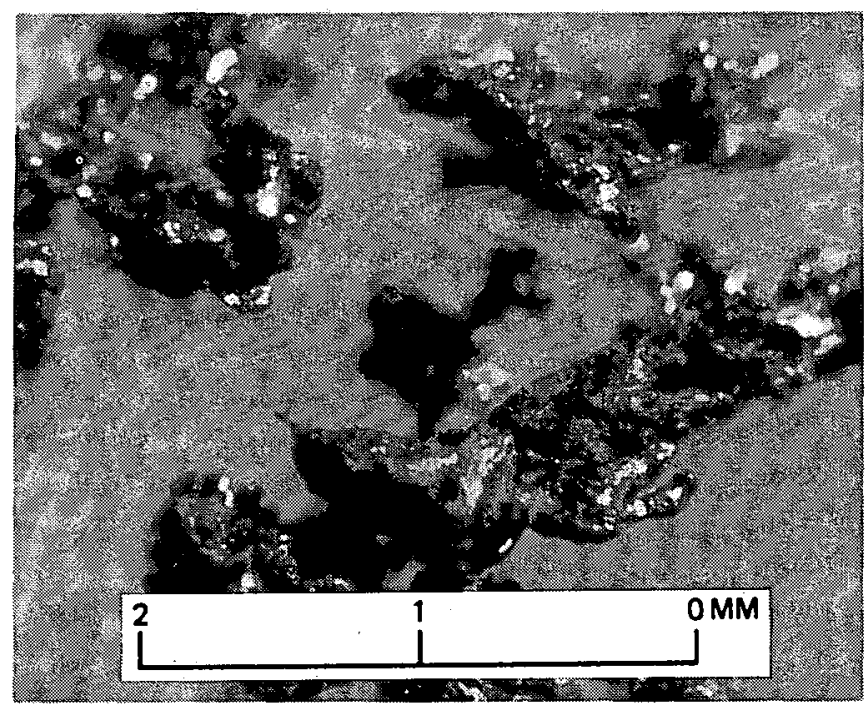

FIGURE 2g

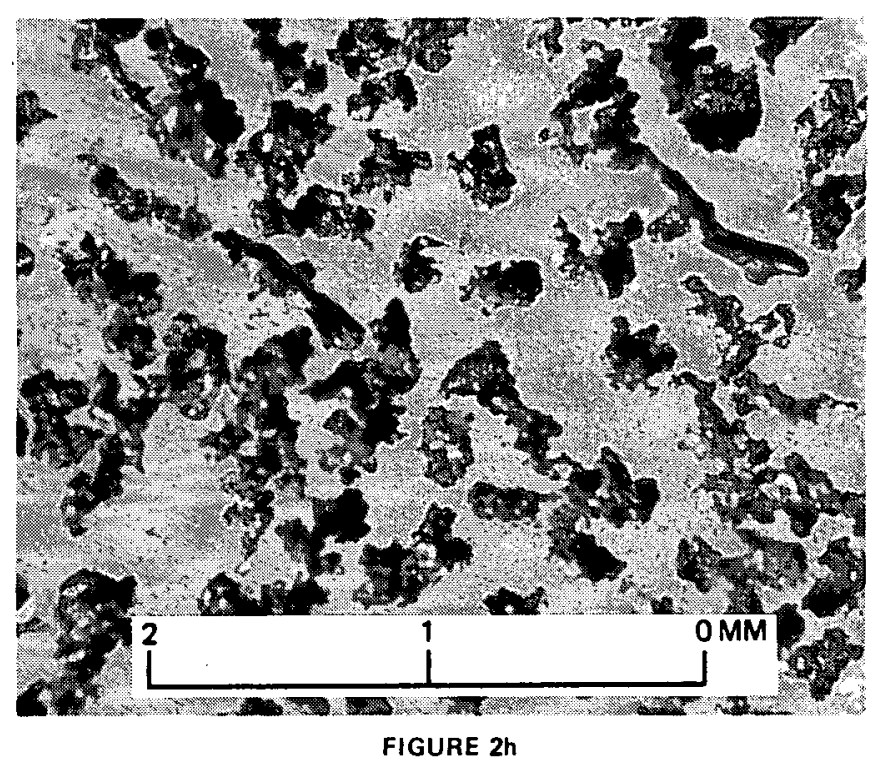

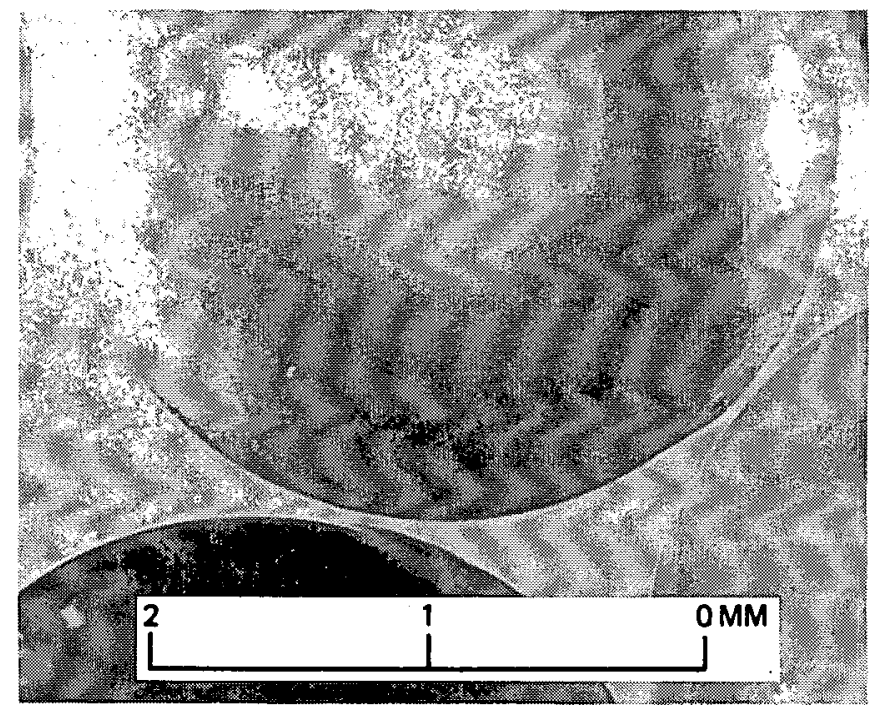

FIGURE 2i

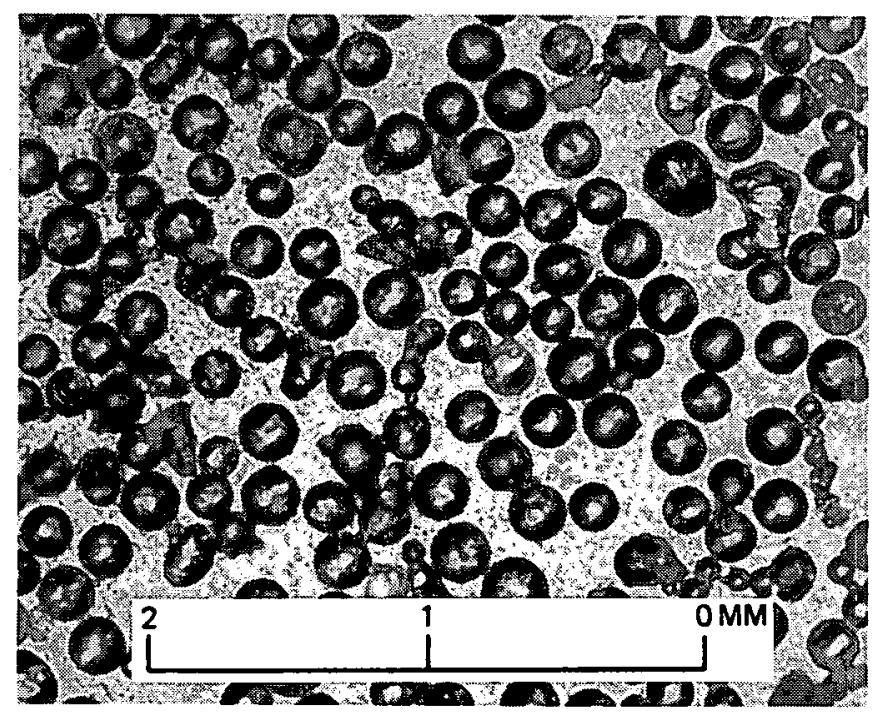

FIGURE 2j

FIGURE 2f: Metal 1, Bronze filter-making powder. Alcan Aluminum Corp. grade MD 46 HP lot 1984.

FIGURE 2g: Metal 2, Stainless steel powder, 316L,25/50 mesh. Hoeganaes Corp., lot 12-35398.

FIGURE 2h: Metal 3, Stainless steel powder, 316L, 48/100 mesh. Glidden Metals, lot 812525.

FIGURE 2i: Glass 1, Soda-lime glass beads, 3mmdia. Scientific Products G6000-1.

FIGURE 2j: Glass 2, Homogenizing beads, $0.2 \mathrm{~mm}$ dia. The Vertis Co., No.16-220. 
For the experiment these granular materials were compacted into cartridges that held the grains firmly and provided for fluid to enter and leave the porosity of the compact. The compacts were characterized in individual cartridges and results are shown in Table 1.

In the granular compacts, different shapes and dimensions of the pore structures were expected to yield unequal hydrodynamic conditions among cartridges. In turn, those might provide different physico-chemical environments under which the deposition reactions could take place.

Table 1: DESCRIPTION OF FILLED CARTRIDGES BEFORE EXPOSURE TO GEOTHERMAL FLUID

SUBS. CART. DEPTH VOLUME POROSITY

\begin{tabular}{|c|c|c|c|c|c|}
\hline & & & $\mathrm{cm}$ & $\mathrm{cm}^{3}$ & \\
\hline Sand & $\begin{array}{l}1 \\
1 \\
1 \\
1\end{array}$ & $\begin{array}{r}3 \\
4 \\
6 \\
20\end{array}$ & $\begin{array}{l}3.3 \\
3.6 \\
3.8 \\
3.3\end{array}$ & $\begin{array}{l}44.7 \\
47.5 \\
53.7 \\
46.4\end{array}$ & $\begin{array}{l}.37 \\
.34 \\
.36 \\
.36\end{array}$ \\
\hline Sand & $\begin{array}{l}2 \\
2\end{array}$ & $\begin{array}{l}10 \\
12\end{array}$ & $\begin{array}{l}3.4 \\
3.5\end{array}$ & $\begin{array}{l}48.6 \\
51.7\end{array}$ & $\begin{array}{l}.32 \\
.35\end{array}$ \\
\hline Sand & $\begin{array}{l}3 \\
3\end{array}$ & $\begin{array}{l}13 \\
14\end{array}$ & $\begin{array}{l}3.3 \\
3.4\end{array}$ & $\begin{array}{l}47.7 \\
50.0\end{array}$ & $\begin{array}{l}.35 \\
.34\end{array}$ \\
\hline Sand & $\begin{array}{l}4 \\
4\end{array}$ & $\begin{array}{l}21 \\
22\end{array}$ & $\begin{array}{l}3.4 \\
3.5\end{array}$ & $\begin{array}{l}47.7 \\
50.2\end{array}$ & $\begin{array}{l}.37 \\
.38\end{array}$ \\
\hline Glass & $\begin{array}{l}1 \\
1\end{array}$ & $\begin{array}{r}5 \\
18\end{array}$ & 3.6 & $\begin{array}{l}43.1 \\
51.5\end{array}$ & $\begin{array}{l}.37 \\
.36\end{array}$ \\
\hline Glass & $\begin{array}{l}2 \\
2\end{array}$ & $\begin{array}{r}8 \\
19\end{array}$ & $\begin{array}{l}3.6 \\
3.6\end{array}$ & $\begin{array}{l}51.8 \\
52.3\end{array}$ & $\begin{array}{l}.35 \\
.36\end{array}$ \\
\hline Metal & $\begin{array}{l}1 \\
1\end{array}$ & $\begin{array}{r}1 \\
17\end{array}$ & $\begin{array}{l}3.8 \\
3.6\end{array}$ & $\begin{array}{l}53.2 \\
52.8\end{array}$ & $\begin{array}{l}.38 \\
.37\end{array}$ \\
\hline Metal & $\begin{array}{l}2 \\
2 \\
2\end{array}$ & $\begin{array}{r}2 \\
7 \\
15\end{array}$ & $\begin{array}{l}3.4 \\
3.6 \\
3.4\end{array}$ & $\begin{array}{l}44.7 \\
50.4 \\
48.9\end{array}$ & $\begin{array}{l}.66 \\
.67 \\
.68\end{array}$ \\
\hline Metal & $\begin{array}{l}3 \\
3\end{array}$ & $\begin{array}{r}9 \\
16\end{array}$ & $\begin{array}{l}3.1 \\
3.6\end{array}$ & $\begin{array}{l}45.8 \\
52.0\end{array}$ & $\begin{array}{l}.63 \\
.64\end{array}$ \\
\hline Rock & 1 & 25 & 2.3 & 25.4 & .18 \\
\hline Rock & 2 & 26 & 2.1 & 20.5 & .16 \\
\hline
\end{tabular}

\section{Substrate Holders}

Cartridges for holding the granular substrates were fabricated from nickel crucibles (Fig $3)$. The open ends of the crucibles were flared so as to mate to and be held in an ordinary plumbing union. The bottoms were perforated with drilled holes approximately $3 \mathrm{~mm}$ in diameter so that $1 / 3$ to $2 . / 3$ of the area was open. In order to retain the granular substrates within the cartridges circular screens of 50 mesh stainless steel were cemented to the inside bottoms of the cartridges with silicone rubber cement. Additionally, a second screen of 100 mesh stainless steel (150 mesh for G2 and M3) was made snug over the first but not cemented.

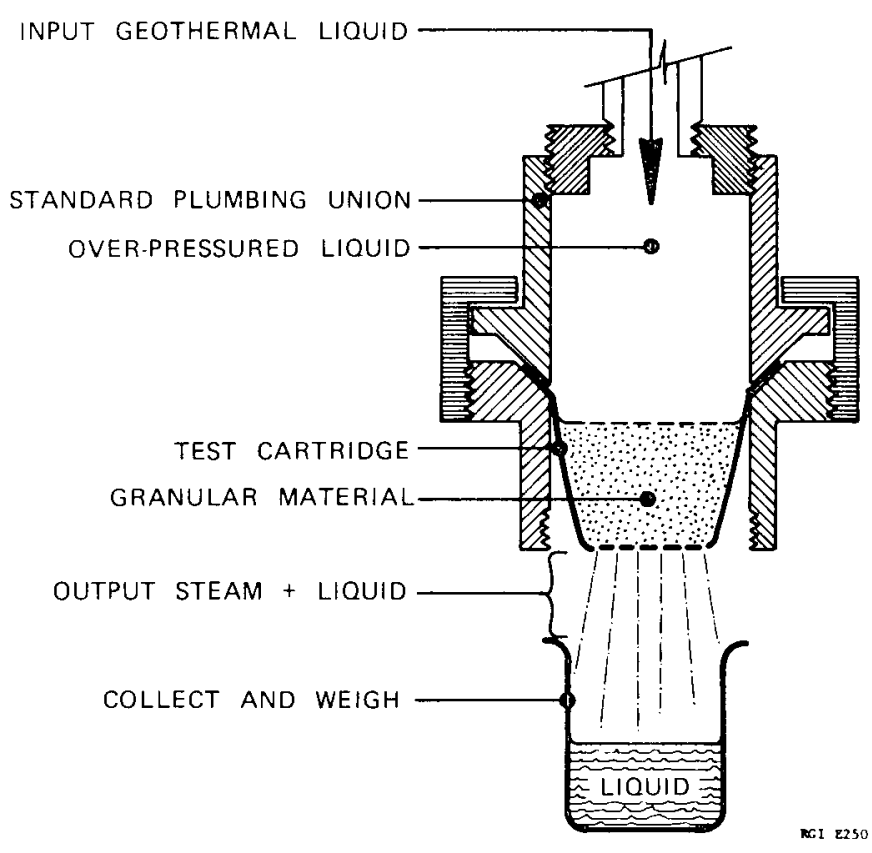

FIGURE 3: Setup for flashing geothermal fluid in cartridges of granular substrates.

A thin layer of silicone rubber cement was spread over the inside walls of the cartridge just before the granular substrate was added. This addition eliminated fluid flow paths along the walls. The aranular substrates were then poured into the cartridge and settled by vibrating the assembly with a 60 hertz tool.

The lid assembly consisted of two screens and a perforated stainless steel lid. Two screens separated the lid from the granular materials, as at the bottom. The coarser screen was cemented to the lid with silicone rubber before the filling operation.

The lid was crimped into the shape of a shallow pan, and sized and positioned so that the crimped edge bit into the sides of the crucible below the flare. This allowed the lid to be seated solidly $\left(3\right.$ to $\left.4 \mathrm{~kg} / \mathrm{cm}^{2}\right)$ on the contents and maintain a degree of compression on them throughout subsequent manipulations.

The two rock samples were mounted inside cartridges after being shaped to fit smoothly against the walls. They were oriented so that fluid flow would be parallel to the bedding planes. Their thicknesses were less than the inside height of the cartridges and 3 to $12 \mathrm{~mm}$ of space was between their flat, parallel surfaces and the lidibottom of the cartridges. Silicone rubber cement held them in place and blocked fluid flow at the cartridge walls.

Field Plumbing

In the field, three unions for holding cartridges were connected in parallel to 1 -inch stainless piping which in turn was connected to the 12-inch geothermal production line (Fig 4). A 1 -inch full-flow ball valve assured that the 1 -inch 1 ine capacity exceeded the collective 


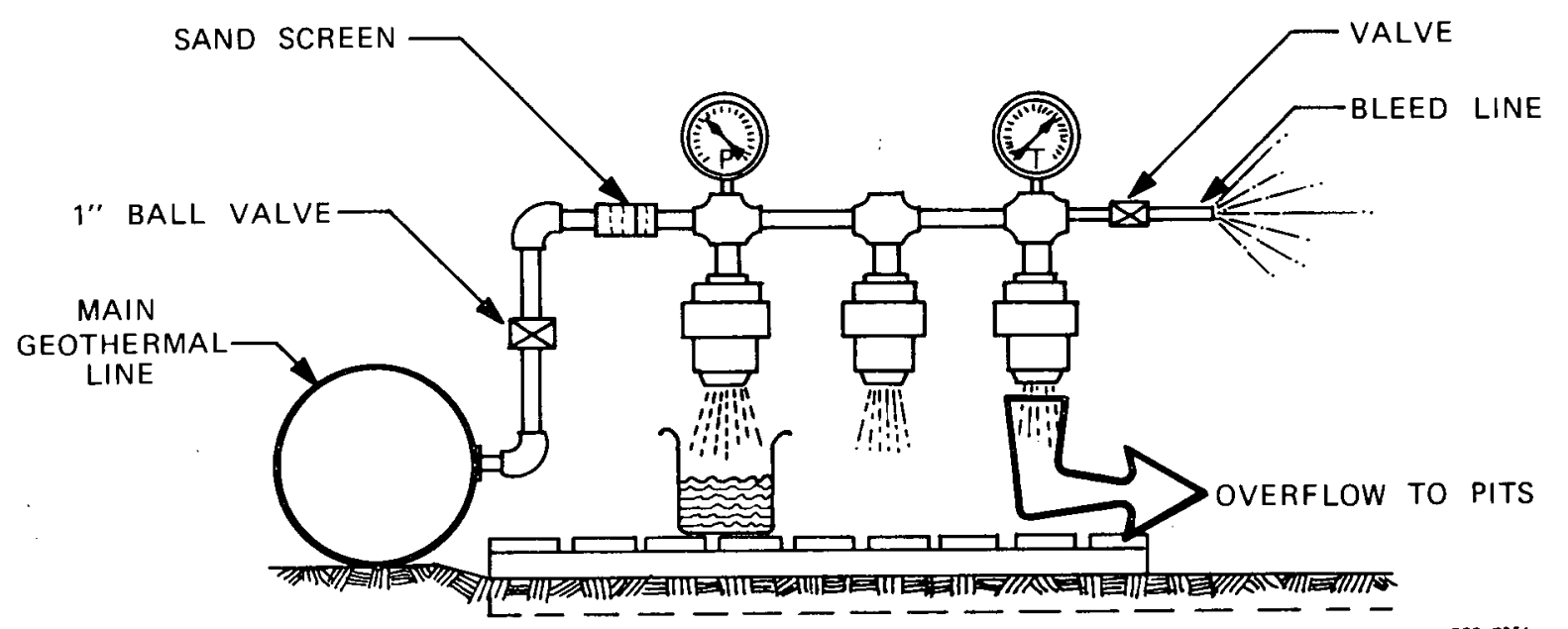

261251

FIGURE 4: Field setup for exposing cartridges to geothermal fluid.

transmissibility of the cartridges so that single-phase liquid always would be present at the 1 ids of the cartridges. The 1 -inch 1 ine was insulated by wrapping with foil-covered fiberglass.

Pressure and temperature were sensed with dial gauges placed in the 1 -inch line near the cartridges. Those readings were taken to indicate conditions at the perforated $1 \mathrm{ids}$ of the cannisters. A bleed 1 ine and valve were provided at the end of the 1 ine so that if flow rates through the cartridges became slow the input temperature could be sustained.

During the first field experiments, sand carried by the geothermal fluid collected on the tops of cannisters, especially the more transmissive ones. This resulted in an unmeasured pressure drop there and in some cases, flashing was initiated above the lids. For subsequent experiments, a filter for suspended solids was placed upstream. The assembly was shut down, cleaned, and refurbished when the downstream pressure, measured downflow of the filters, approached the flash pressure for the fluid, approximately $7.0 \mathrm{~kg} / \mathrm{cm}^{2}$ absolute.

\section{Field Monitoring}

Most cartridges were on line for a total of 2 to 5 hours, but cleanout of the sand filter required shutdown oftener than that. Thus, the exposure of each cartridge to geothermal fluid was made up of a succession of intervals, usually 3 in number. Each interval was characterized by a continual but inconstant decrease in pressure from an initial value near $10 \mathrm{~kg} / \mathrm{cm}^{2}$ absolute to a final value near $8 \mathrm{ka} / \mathrm{cm}^{2}$. A vapor phase begins to develop from this geothermal liquid at about $7.0 \mathrm{kq} / \mathrm{cm}^{2}$ and care was taken to assure that pressure at the cartridge lids always exceeded that. Thus, flashing always was initiated within the cartridges, except as noted above and in tables.

Mass flow rate and cumulative mass flow of the geothermal fluid are both required for each cartridge's. exposure during a field run. The mass flow rates through the cartridges were determined by collecting liquid which issued from them. A stopwatch was used to time the collection period, then the collection vessel with liquid was weighed on a standardized scale. The incremental mass flow was larger than the weighed liquid due to steam 1osses. The field-determined rates for 1 iquid flow were inflated to account for $11 \%$ of the input fluid being lost as steam, an adjustment based on input temperature of $158^{\circ} \mathrm{C}$ and collection at $100^{\circ} \mathrm{C}$ and atmospheric pressure.

Splashing in the collection vessel was generally not a complication, and no allowance for splashing losses was made. Generally, repeated attempts at collection could be made until losses of liquid due to splashing were judged negligible. For some of the more highly transmissive cartridges, fluid was still flashing as it entered the collection vessel and for these, splashing was more troublesome. One substrate, M2, yields cartridges of such high transmissibility that rates for only one of 3 cartridges were successfully measured. Adequate data were obtained in al1 other cases.

Cumulative flows for each cartridge were determined by plotting the adjusted measured rates vs. running time. The points in each test interval were connected by smooth 1 ines and extrapolated to the boundaries of the intervals (Fig 5). Areas under the rate curves were integrated with a planimeter to determine the mass throughputs. The total mass throughput per cannister ranged from 15 to $3800 \mathrm{~kg}$, the median was near $1500 \mathrm{~kg}$. These data and others are listed in Table 2 .

After field exposure, the cartridges were stored in flashed geothermal liquid. This maintained their saturation through transport to the laboratory where further studies were made.

Porosity

Pore volumes inside the cannisters were based on weight differences between dry and watersaturated conditions except for substrates G1, M1, and M2. The saturation measurement was made immediately after the flow rate measurement, utilizing the thorough flushing of that test to 


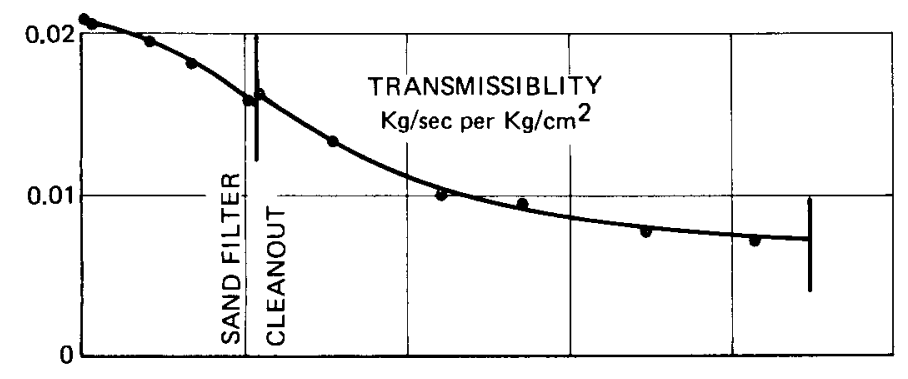

Table 2: FIELD EXPOSURES
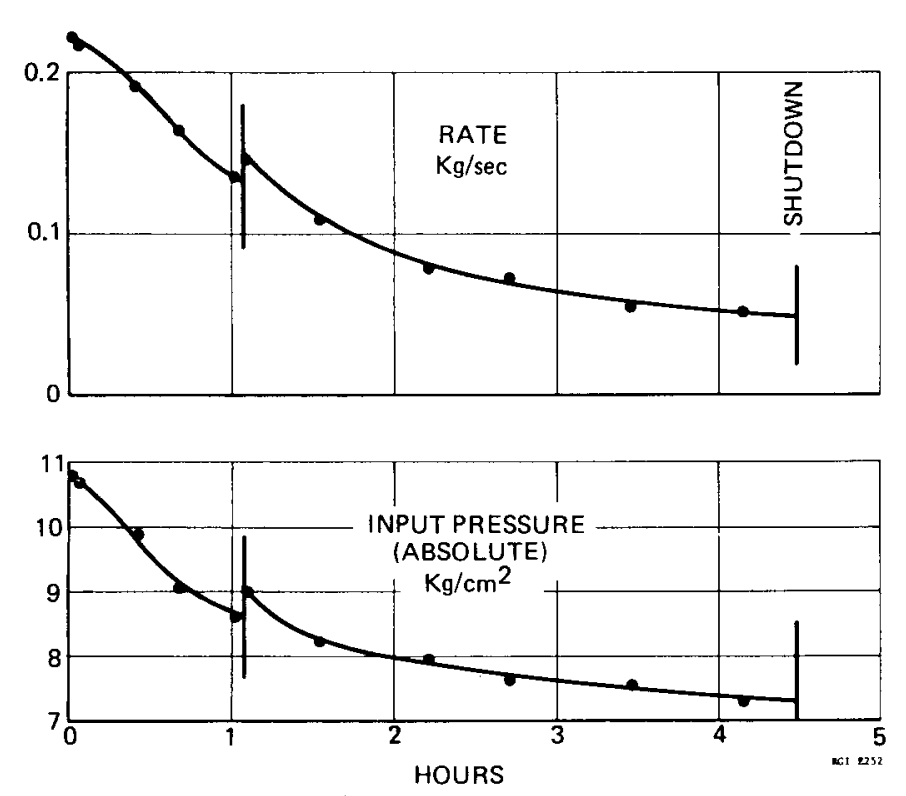

FIGURE 5: Example of flow data; cartridge 22

assure that pores were saturated. Substrates G1, $M 1$ and M2 had too 1 ittle capillarity to retain liquid. Their porosities were determined by injecting water from a calibrated syringe through a fixture attached to the bottoms. Empty weights for all cannisters were available from weighings which followed a step of drying at $100^{\circ}$ to $140^{\circ} \mathrm{C}$. An allowance for the porosity of screens and end spaces was made. Data are shown in Table 1.

\section{Residual Scale Components in Liquid Samples}

Samples of effluent liquid from the cartridges were collected at intervals and stored without preservatives in $250 \mathrm{ml}$ polethylene bottles, pending transport to the laboratory for analysis. Chemical analysis for calcium was done by titration with EDTA (.00125 molar) using the indicator F241, adapted from a method described in (4). This method determines the sum of $\mathrm{Ca}+\mathrm{Mq}$. However, the $\mathrm{Mg}$ is scarce in East Mesa fluid (near $0.2 \mathrm{ppm}$ ) so that unadjusted results of the titration can be taken to indicate $\mathrm{Ca}$ content. The F241 indicator provides a sharper end point at the EDTA concentration used than do $\mathrm{Ca}-\mathrm{spec}$ ific methods. Sensitivity of the analysis is near 0.1 ppm Ca.

Analyses for $\mathrm{CO}_{3}$ and $\mathrm{HCO}_{3}$ were done by titration with sulfuric acid $(0.05$ molar) using successively the indicators phenolphthalein and methyl orange in the same aliquot. Sensitivity is near $10 \mathrm{ppm} \mathrm{HCO}_{3}$.

\begin{tabular}{|c|c|c|c|c|}
\hline SUBS. & CART. & $\begin{array}{c}\text { HOURS } \\
\text { ON LINE }\end{array}$ & $\begin{array}{c}\mathrm{kg} \text { FLUID } \\
\text { THRUPUT } \\
\end{array}$ & FILTERED \\
\hline S1 & $\begin{array}{r}3 \\
4 \\
6 \\
20\end{array}$ & $\begin{array}{l}1.98 \\
2.22 \\
2.68 \\
5.37\end{array}$ & $\begin{array}{r}83 \\
590 \\
725 \\
3430\end{array}$ & $x$ \\
\hline S2 & $\begin{array}{l}10 \\
12\end{array}$ & 5.35 & 3830 & $x$ \\
\hline \$3 & $\begin{array}{l}13 \\
14\end{array}$ & $\begin{array}{l}3.73 \\
4.50\end{array}$ & $\begin{array}{r}620 \\
2650\end{array}$ & $x$ \\
\hline S4 & $\begin{array}{l}21 \\
22\end{array}$ & $\begin{array}{l}2.70 \\
4.50\end{array}$ & $\begin{array}{r}720 \\
1650\end{array}$ & $\begin{array}{l}x \\
x\end{array}$ \\
\hline G1 & $\begin{array}{r}5 \\
18\end{array}$ & $\begin{array}{r}0 \\
2.82\end{array}$ & $\begin{array}{r}0 \\
1000\end{array}$ & \\
\hline G2 & $\begin{array}{r}8 \\
19\end{array}$ & $\begin{array}{l}3.73 \\
2.90\end{array}$ & $\begin{array}{r}385 \\
2430\end{array}$ & $x$ \\
\hline M1 & $\begin{array}{r}1 \\
17\end{array}$ & $\begin{array}{l}4.52 \\
5.73\end{array}$ & $\begin{array}{l}2880 \\
2916\end{array}$ & $x$ \\
\hline M2 & $\begin{array}{r}2 \\
7 \\
15\end{array}$ & $\begin{array}{r}2.22 \\
.17 \\
.70\end{array}$ & & \\
\hline M3 & $\begin{array}{r}9 \\
16\end{array}$ & $\begin{array}{l}5.25 \\
2.82\end{array}$ & $\begin{array}{l}3960 \\
1350\end{array}$ & $x$ \\
\hline $\mathrm{R} 1$ & 25 & 9.73 & 142 & \\
\hline R2 & 26 & 2.90 & 6.7 & \\
\hline
\end{tabular}

A nominal composition for the unflashed geothermal liquid is shown in Table 3 . During the experimental period there were small trends in both the $\mathrm{Ca}$ concentration and in the initial $\mathrm{HCO}_{3}$ concentration, but these effects are suspected to be negligible compared to other factors affecting the $\mathrm{CaCO}_{3}$ deposition.

TABLE 3: COMPOSITION OF EXPERIMENTAL FLUID E.M. 56-30 Pre-Flash Parts per Million by Weight

\begin{tabular}{|c|c|c|c|c|c|}
\hline $\mathrm{Na}$ & 595 & $\mathrm{Cl}$ & 535 & $\mathrm{CO}_{2}$ & 440 \\
\hline$k$ & 56 & $\mathrm{HCO}_{3}$ & 525 & $\mathrm{~N}_{2}$ & 45 \\
\hline $\mathrm{Li}$ & .85 & $\mathrm{CO}_{3}$ & .11 & $\mathrm{CH}_{4}$ & .8 \\
\hline $\mathrm{Ca}$ & 6.3 & $\mathrm{SO}_{4}$ & 180 & $\mathrm{H}_{2} \mathrm{~S}$ & .05 \\
\hline $\mathrm{Mg}$ & .2 & $F$ & 2.3 & $\mathrm{SiO}_{2}$ & 140 \\
\hline $\mathrm{Sr}$ & .4 & B & .4 & & \\
\hline $\mathrm{NH}_{4}$ & 2.0 & $\mathrm{PO}_{4}$ & $<.1$ & & \\
\hline $\mathrm{Fe}$ & .05 & & & & \\
\hline
\end{tabular}


RESULTS:

Framework for Selecting Data

The approach used here will emphasize the phenomena as processes. In this point of view, the observer moves along with the fluid as it passes through the compact and one notes the transitions involved as conditions change and particular events occur. In this view, the same basic pattern of events occurs in each compact, but because of different physical characteristics among the compacts these events happen neither in the same relative positions nor to the same degree. This approach allows one to be better focused on the similarities of response among the substrates while recognizing their differences, than do alternative viewpoints. Additionally and more importantly, the point of view used here does better in accommodating the features of non-equilibrium that are involved. This non-equilibrium has immense significance to interpreting (and to manipulating) the events which accompany flashing of geothermal liquids in general.

Viewing the flashing event as a process enables one to place the non-equilibrium aspects into a frame of reference based on the physical conditions of temperature, available space, and pressure gradients along the flow path. It is the transitions within this frame that set the stage for ionic and molecular-level events that are the concommitant chemical reactions. These chemical reactions are discreet events, in contrast to the physical conditions that are impressed on the space in which the events tend to occur.

One may reconcile non-equilibrium as merely the time involved with getting the ions and molecules adjusted to changed surroundings. But, that is not enough to accurately describe flashing, and the view of "process" provides the necessary extra. By following the components of a geothermal fluid through the sequence of pressure drops, temperature changes, space availabilities, proximities of surfaces et al. that affect the chemical reactions, one introduces also the aspect of appropriate timing for certain chemical events. Chemical events favored at one position in the flow path may not occur there for the reason that sufficient time simply is not available at that location. But more than that, those events may not take place elsewhere either because at positions further down the flow path the intensive conditions may be no longer appropriate. Thus, non-equilibrium in the context of flashing geothermal fluids is more than just a delayed response, it may also include lost opportunities for certain reaction events.

\section{Flashing in the Experimental Cartridges}

Geothermal liquid enters the openings of the lids and passes through the screens whence it begins a non-Darcian flow along a tortuous path and (presumably) a uniform pressure gradient. The pressure gradient is due jointly to the viscous interaction with the granular substrate and to inertial/pressure effects downstream which are propagated up the flow path. Eventually, the fluid moves along the pressure gradient to where the actual pressure has diminished to the flash pressure for the liquid. 1 At that place the pressure gradient steepens and the mixed-phase fluid begins to develop and to accelerate.

The supersaturation of $\mathrm{CaCO}_{3}$ hegins to build up in the residual liauid according to the degree that $\mathrm{CO}_{3}=$ increases in concentration. The $\mathrm{CO}_{3}=$ buildup is a joint effect of reduced temperature and reduced chemical activity of $\mathrm{CO}_{2}$. The actual deposition of $\mathrm{CaCO}_{3}$ occurs initially by nucleation of calcite and/or aragonite crystals on the surfaces of grains of the substrate and subsequently (and mainly) by the processes of crystal growth that operate within and beneath 1 iauid boundary layers.

By the time fluid reaches the exit face of the cartridge, the velocity has become high and in severe cases fluid boundary layers may be thin, compared to upstream locations: Upon exiting the cartridge the residual 1 iquid may still possess some superheat, and explosive flashing may accompany the emeraence of the 2 -phase fluid into the atmosphere.

For this process four kinds of information have been measured to describe it.

1) Fluid transmissibilities and flow rates $c$ an be used to deduce something about the pressure gradients.

2) The amounts of $\mathrm{CaCO}_{3}$ deposited in the cartridges and the amounts remaining in the residual 1 iquid after discharge describe a chemical efficiency for the deposition process that can be related to a theoretical context.

3) The physical appearance and distribution of the $\mathrm{CaCO}_{3}$ within the compact reflects the micro processes of crystal arowth.

4) The conditions of pressure, temperature and space identify the physical houndaries of the phenomena.

The data are presented next, with other descriptive items that focus more sharply on their uniqueness irrespective of context.

Fluid Transmissibilities of the cartridges are quantified in units of mass rate per pressure increment ( $\mathrm{kg} / \mathrm{sec}$ per $\mathrm{kg} / \mathrm{cm}^{2}$ ) commonly abbreviated as $\mathrm{cm}^{2} / \mathrm{sec}$. The values for transmissibilities based on different contexts of measurement are listed in Table 4.

Single-phase liquid transmissibilities (distilled water at $18^{\circ} \mathrm{C}$ ) were obtained for all cartridoes both before and after their field exposures. The cartridaes were seated in a

1This flash pressure is the sum of the water vapor pressure and the vapor pressures due to all other components in the fluid, of which $\mathrm{CO}_{2}$ is the most important to the chemical reactions involved. Al though $\mathrm{N}_{2}$ and $\mathrm{CH}_{4}$ and others are present in the fluid, their content is minor and the description of the process does not suffer from ignoring them. 
TABLE 4: FLUID TRANSMISSIBILITIES

\begin{tabular}{|c|c|c|c|c|c|}
\hline \multirow[b]{3}{*}{ SUBST. } & \multirow[b]{3}{*}{ CART. } & \multicolumn{4}{|c|}{$\mathrm{g} / \mathrm{sec}$ per $\mathrm{kg} / \mathrm{cm}^{2}$} \\
\hline & & \multicolumn{2}{|c|}{ 1-PHASE } & \multicolumn{2}{|c|}{ 2-PHASE } \\
\hline & & BEFORE & AFTER & INITIAL & FINAL \\
\hline SI & $\begin{array}{r}3 \\
4 \\
6 \\
20\end{array}$ & $\begin{array}{l}42.3 \\
59.6 \\
40.8 \\
89.1\end{array}$ & $\begin{array}{l}48.0 \\
24.6 \\
17.1 \\
57.1\end{array}$ & $\begin{array}{l}6.7 \\
27 . \\
23 . \\
31 .\end{array}$ & 21. \\
\hline S2 & $\begin{array}{l}10 \\
12\end{array}$ & 94.8 & 38.6 & 34. & 15. \\
\hline S3 & $\begin{array}{l}13 \\
14\end{array}$ & $\begin{array}{l}49.3 \\
44.7\end{array}$ & $\begin{array}{l}16.3 \\
2.84\end{array}$ & $\begin{array}{l}20 . \\
26 .\end{array}$ & 18. \\
\hline S4 & $\begin{array}{l}21 \\
22\end{array}$ & $\begin{array}{l}25.6 \\
17.3\end{array}$ & $\begin{array}{l}8.45 \\
1.28\end{array}$ & $\begin{array}{l}17 . \\
23 .\end{array}$ & $\begin{array}{l}7.9 \\
8.3\end{array}$ \\
\hline GT & $\begin{array}{r}5 \\
18\end{array}$ & $\begin{array}{l}1089 \\
2560\end{array}$ & 66.5 & 19. & \\
\hline G2 & $\begin{array}{r}8 \\
19\end{array}$ & $\begin{array}{l}77.4 \\
96.4\end{array}$ & $\begin{array}{l}3.39 \\
74.2\end{array}$ & $\begin{array}{l}4.4 \\
36 .\end{array}$ & 28. \\
\hline M1 & $\begin{array}{r}1 \\
17\end{array}$ & $\begin{array}{l}226 \\
250\end{array}$ & $\begin{array}{l}71.1 \\
70.8\end{array}$ & $\begin{array}{l}46 . \\
45 .\end{array}$ & $\begin{array}{l}2.2 \\
6.9\end{array}$ \\
\hline M2 & $\begin{array}{r}2 \\
7 \\
15\end{array}$ & $\begin{array}{r}815 \\
862 \\
1044\end{array}$ & $\begin{array}{l}299 \\
844 \\
859\end{array}$ & 45. & \\
\hline M3 & $\begin{array}{r}9 \\
16\end{array}$ & $\begin{array}{l}201 \\
209\end{array}$ & $\begin{array}{l}82.1 \\
70.1\end{array}$ & $\begin{array}{l}33 . \\
59 .\end{array}$ & $\begin{array}{l}15 . \\
16 .\end{array}$ \\
\hline $\mathrm{RT}$ & 25 & 0.022 & 20.056 & 0.95 & 0.12 \\
\hline R2 & 26 & $<10^{-2}$ & $<10^{-2}$ & 0.30 & 0.23 \\
\hline
\end{tabular}

plumbing union similar to the field setup, above which was mounted a 1-liter graduated cylinder (Figure 6). The cylinder was drilled and tapped at the bottom to accept a $1 / 2$-inch pipe nipple which was fitted to the union with a bushing. Water in the cylinder passed directly through the nipple to the cartridge in the union. The graduations of the cyl inder served to indicate both liquid pressure and volume increments during the flow rate measurements.

The cylinder was filled with distilled water and the falling liquid level was timed as it passed several reference marks. Usually five time stops were obtained in a single fall (run). The heights of the reference marks were measured from the bottom of the cartridge which was unobstructed during a run. Three to five "runs" were timed for each cartridge. The multiple flushings minimized trapped air inside the compacts. Between runs the liquid level was maintained above the cartridge top to avoid ingress of air.

For cartridges of very low transmissibility the liquid levels fell too slowly for the graduations on the cylinder to be practical estimates of volume increments. In those cases, the liquid that was transmitted in timed intervals was weighed to yield data about mass.

The multiple estimates of transmissibility, obtained in single runs could be used to assess whether the flow through the compacts was in accordance with Darcy's law and most of the compacts conformed to that fairly well for this measurement. Notable exceptions were G1 (3-mm diameter spheres), $M 1$ and $M 2$. These results contrast with the field context in which the 1 -phase segment of the flow path for the geothermal liquid is not Darcian.

Changes in transmissibility due to field exposures were determined by remeasuring transmissibilities with the lab setup after the field exposures. The results are shown in Table 4.

Transmissibilities are proportional to permeability in the case of the 1-phase measurement made before the field runs. Since the geometries of the cartridges are similar, the numerical permeabilities in darcies can be given approximately by multiplying the transmissibilities $\left(\mathrm{cm}^{2} / \mathrm{sec}\right)$ by 250 .

For the post field-exposure measurement, the porosity is not uniform, because deposition of $\mathrm{CaCO}_{3}$ occurred in narrow regions of the pore space, hence those measured transmissibilities are results of composite properties of the different zones and a numerical permeability cannot be obtained. The 2-phase measure made near the end of the field exposure shows the large effect that small $\mathrm{CaCO}_{3}$ depositions have on the flow properties.

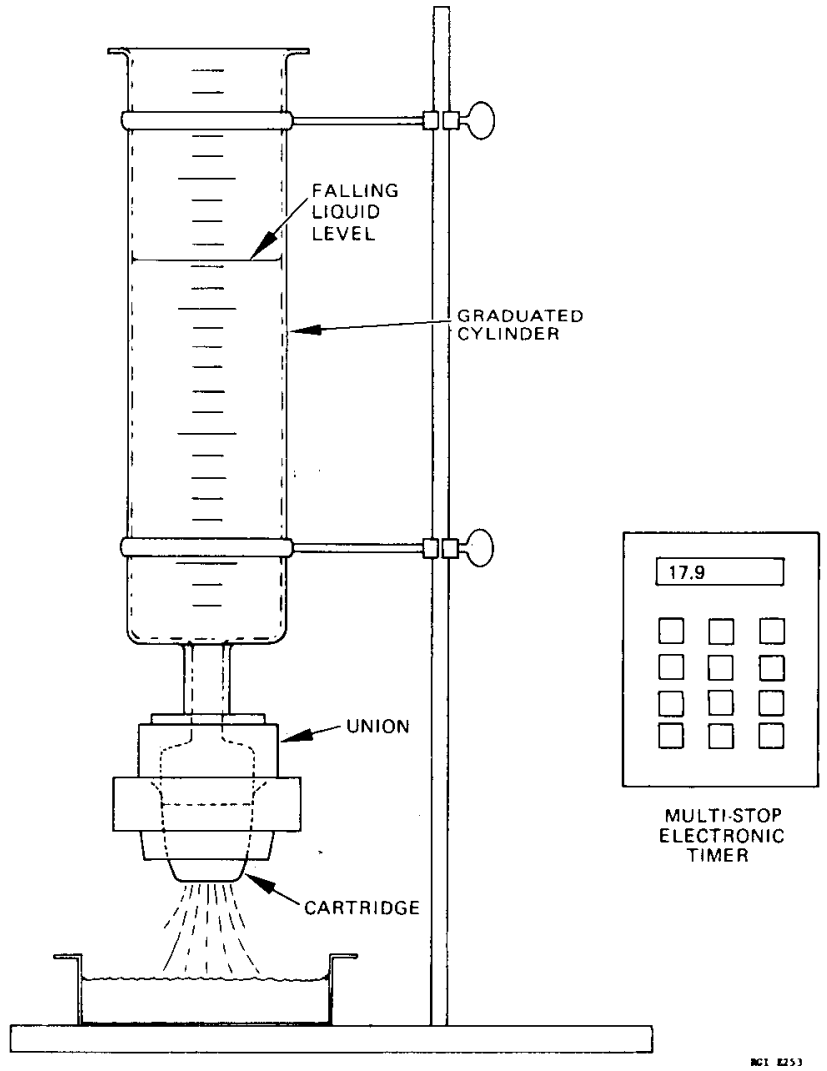

FIGURE 6: Setup for measuring 1-phase transmissibilities of cartridges. 
$\mathrm{CaCO}_{3}$ Deposition,

Amounts of $\mathrm{CaCO}_{3}$ deposition were estimated in two ways: changes in weight of the cartridges due to field exposure and integrations of $\mathrm{Ca}$ concentrations over the "liquid throughputs. Results from the chemical basis generally are larger than the weight gain. (Table 5). (Chemical data are not available for discharges from cartridges 1 thru 6.) Both methods are subject to errors which differ from cartridge to cartridge. During shutdowns for cleaning sand from the filter, some cartridges became partly dried by the residual heat in the fittings. Plausibly, some $\mathrm{CaCO}_{3}$ particles may have become detached from their site in the substrate and flushed away upon restarting, yielding a "too small" weight gain. However, subsequent observations of the $\mathrm{CaCO}_{3}$ particles in thin sections of the compacts suggest that their attachments to the grains of substrate are for the great majority, very robust.
Conversely, it seemed plausible that small suspended particulates in the geothermal fluid might pass the sand filter and lodge in the cartridges, creating an anomalous weight gain. Such particulates were looked for but not found in the thin sections.

Some cartridges showed weight losses. Whether this is due to dissolution of some grains or to loss of fines is unresolved. However, in all those cases, a deposit of $\mathrm{CaCO}_{3}$ is apparent in the thin sections, so the chemical data is used for estimating total depositions there. Dissolution of substrate may account for some of the weight gains being smaller than the chemical estimates. The best estimates of $\mathrm{CaCO}_{3}$ deposited in the substrates, as listed in Table 5, are individually based on judgments regarding the available data for each cartridge.

TABLE 5: $\mathrm{CaCO}_{3}$ DEPOSITION IN CARTRIOGES

\begin{tabular}{|c|c|c|c|c|c|c|c|c|c|}
\hline \multirow[b]{2}{*}{ Subs. } & \multirow[b]{2}{*}{ Cart. } & \multicolumn{3}{|c|}{. MASS DEPOSITED } & \multicolumn{2}{|c|}{ RELATIVE DEPOSITION } & \multicolumn{3}{|c|}{$\begin{array}{l}\text { DISTRIBUTION } \\
m m \text { FROM EXIT FACE }\end{array}$} \\
\hline & & Wt. Gain & Chem. Basis & Rest Est. & $\mathrm{Ve} / \mathrm{Vp}^{\star}$ & Chem. eff. $\star \star \star$ & Upper Limit & Max. & Lower Limit \\
\hline \multirow[t]{4}{*}{ S1 } & 3 & 1.3 & - & 1.3 & .011 & 1.0 & 4 & 2 & 0 \\
\hline & 4 & 1.1 & - & 1.1 & .0085 & .12 & 4 & 2 & 0 \\
\hline & 6 & 1.0 & - & 1.0 & .0069 & .089 & 5 & 3 & 0 \\
\hline & 20 & -2.4 & 6.10 & 6.1 & .049 & .11 & & & \\
\hline \$2 & $\begin{array}{l}10 \\
10\end{array}$ & 0.6 & -1.54 & 0.6 & .0046 & .010 & 2.5 & 1.5 & 0.5 \\
\hline \multirow[t]{2}{*}{ S3 } & 13 & 2.3 & 3.44 & 2.9 & .022 & .30 & 11. & 3. & 1.5 \\
\hline & 14 & .9 & 1.06 & 1.0 & .0074 & .024 & 2.5 & 1.5 & 0 \\
\hline \multirow[t]{2}{*}{54} & 21 & 1.2 & 1.68 & 1.4 & .011 & .13 & 10 & 1.8 & 0 \\
\hline & 22 & .7 & 3.22 & 2.0 & .015 & .077 & 2.4 & 1.0 & 0.3 \\
\hline \multirow[t]{2}{*}{ G1 } & 5 & & & & & & & & \\
\hline & 18 & 9.5 & 8.32 & 8.9 & .064 & .57 & 38 & 6 & 0 \\
\hline \multirow[t]{2}{*}{ G2 } & 8 & 3.8 & 4.82 & 4.3 & .031 & .72 & 36 & 16 & 2.5 \\
\hline & 19 & -0.9 & 3.0 & 3.0 & .021 & .078 & 2.5 & .1 .1 & 0.3 \\
\hline \multirow[t]{2}{*}{ M1 } & 1 & -.2 & - & & & & & Unclear & \\
\hline & 17 & 0.9 & .65 & 0.8 & .0056 & .017 & 5 & 2.8 & 0.6 \\
\hline \multirow[t]{3}{*}{ M2 } & 2 & 2.6 & - & 2.6 & .021 & - & 8 & 1 & 0 \\
\hline & 7 & 0.0 & 0.0 & 0.0 & - & - & & one vis & ible \\
\hline & 15 & 0.1 & 1.89 & .4 & .003 & - & & Unclea & \\
\hline \multirow[t]{2}{*}{ M3 } & 9 & 1.0 & 2.58 & 1.8 & .015 & .031 & 5 & 0.7 & 0 \\
\hline & 16 & 2.1 & 4.72 & 3.4 & .014 & .16 & 10 & 2 & 0 \\
\hline R1 & 2.5 & -2.0 & 1.05 & 1.05 & .084 & .47 & Discernit & ble on 1 & $y$ at 0 \\
\hline
\end{tabular}

$\star V e / V p=$ volume of $\mathrm{CaCO}_{3} \div$ volume of pores

**Chem. eff.; chemical efficiency $=$ amount of Ca retained $\div$ amount of Ca input 
The amount of $\mathrm{CaCO}_{3}$ deposited can be presented in several ways (Table 5) but since the deposition is non-uniform these amounts cannot readily be correlated with other factors. It is tempting, for example, to relate the change in transmissibility of the cartridges to the deposition of $\mathrm{CaCO}_{3}$. Figure 7 is a scatter diagram that would display a correlation if it existed. None is apparent.

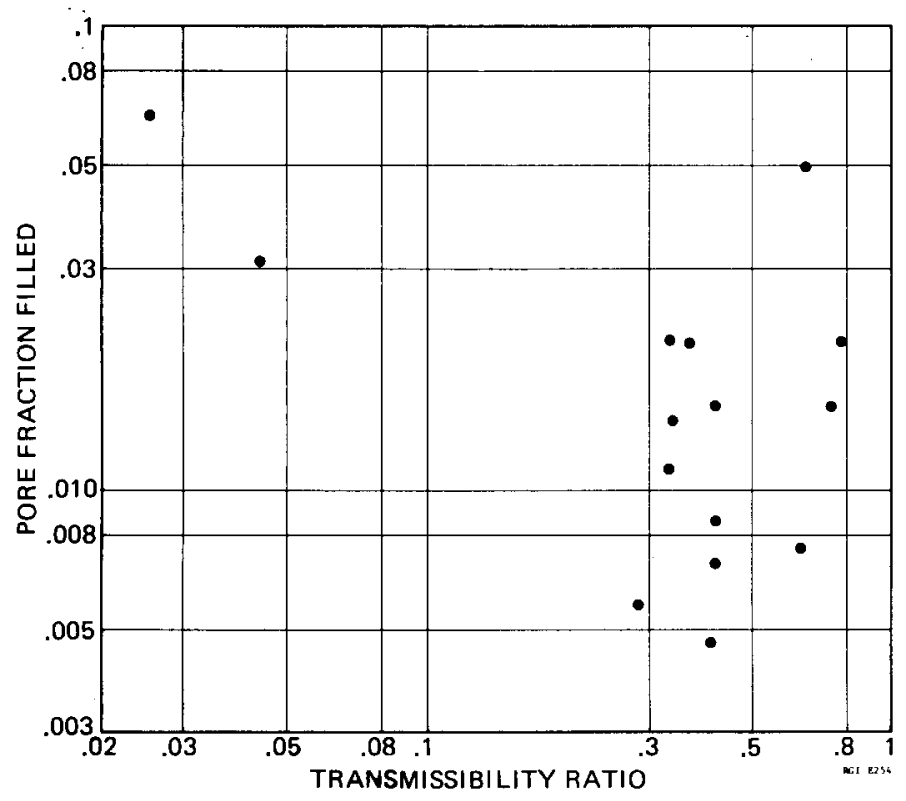

FIGURE 7: Scatter diagram of pore filling vs. ratio of 1-phase transmissibilities, AFTER/BEFORE.

Al so listed in Table 5 are the volumes of $\mathrm{CaCO}_{3}$ deposited as a fraction of the available pore space. The largest value is only $6.4 \%$. Because the deposition is non-uniform this fraction serves only as an insensitive index to the severity of $\mathrm{CaCO}_{3}$ deposition; corresponding transmissibilities were reduced by factors of 2 to 40 .

Neither of the static measures of deposition given above address the context of process. A better indicator for the severity of $\mathrm{CaCO}_{3}$ deposition is the fraction of $\mathrm{Ca}$ entering with the geothermal fluid that is deposited in the cartridge. These values are given in Table 5 and describe a kind of chemical efficiency for the deposition. This efficiency is generally low, several results are in the vicinity of $15 \%$; and for many of the cannisters, chemical efficiency decreased during the experimental runs (Figure 8 ). These observations suggest that the system fails to approach chemical equilibrium very closely.

Distributions of $\mathrm{CaCO}_{3}$ within the cartridges were determined by examining thin sections with a microscope and by photographing. Polymorph identifications were al so made then. Thin sections of the glass and sand compacts were prepared by infusing epoxy into the porosity of the compacts which hardened and maintained integrity during sectioning and polishing. Polished (thick) sections of the metallic compacts were made similarly for examination by reflected light.

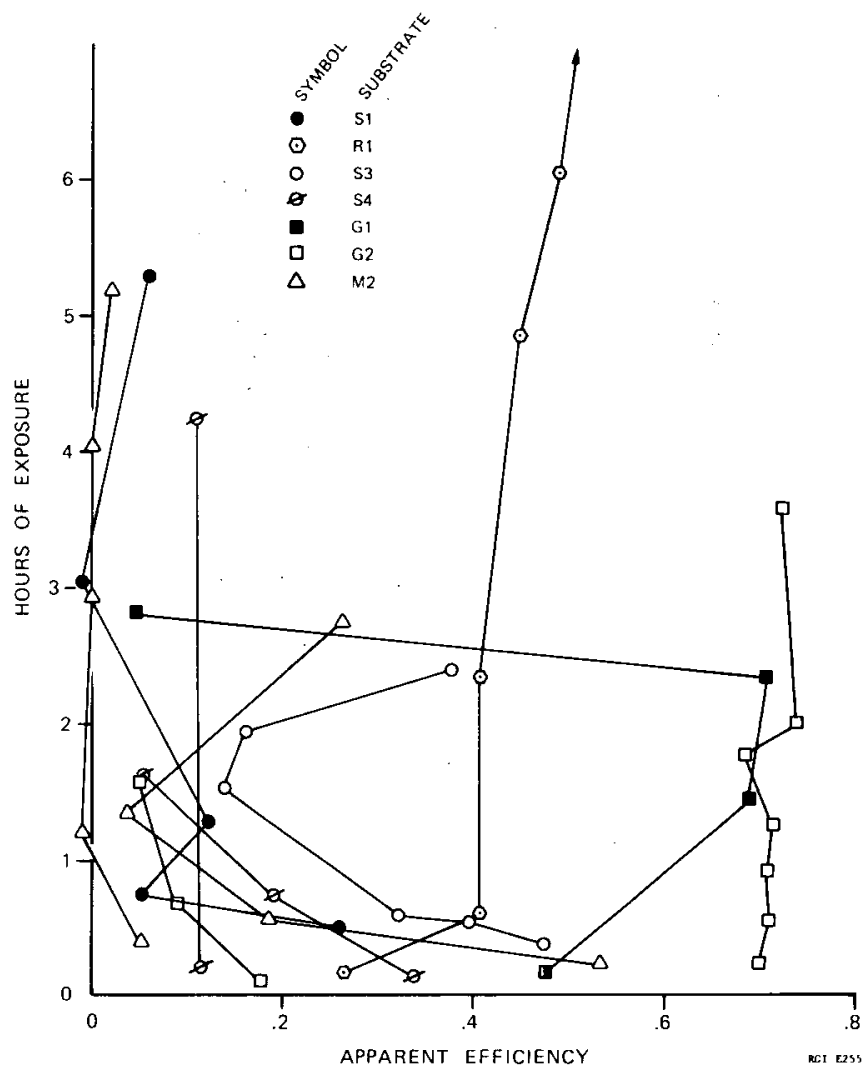

FIGURE 8: Efficiency of $\mathrm{CaCO}_{3}$ deposition vs. time. Deposition commonly is more efficient early in the exposure. Exceptional cases, G2, G1, are less representative because a sand covering caused a heterogeneous matrix for fluid flow.

The $\mathrm{CaCO}_{3}$ exposed by sectioning is found mainly in the last few millimeters of flow paths. Table 5 shows of results of microscopic examinations of thin sections and polished sections. Notably, the positions of maximum deposition are not at the exit faces.

Within the zones of deposition are several interesting features. Among these are: 1) distinct crystal forms of the $\mathrm{CaCO}_{3}$, calcite rhombs vs. aragonite acicules; 2) distribution patterns of $\mathrm{CaCO}_{3}$ crystals on the perimeters of grains of substrate and as pore fillings; 3) number density of $\mathrm{CaCO}_{3}$ crystals across the zones of deposition.

Aragonite and Calcite, two polymorphs of $\mathrm{CaCO}_{3}$, occurred both separately and together in the cartridges. Where they both occurred in the same cartridge the calcite form was dominant only in that part of the deposition zone furthest from the exit face of the cartridge. That is, calcite appears to be favored where the degree of flashing is less. One may infer also that the $\mathrm{pH}$ there is lower, the ratio of $\mathrm{CO}_{3} / \mathrm{HCO}_{3}$ is smaller and, in the earliest stages, the concentration of $\mathrm{Ca}(6.3 \mathrm{ppm})$ exceeds the concentration of $\mathrm{CO}_{3}=$ (initially near $0.1 \mathrm{ppm}$ ). In some cases, aragonite forms exclusively on one side of the zone while calcite forms exclusively on the other.

Cartridges run without the pre-filter accumulated sand on their tops. The most trans- 
missive cartridges were more strongly affected since for those, the sand was less permeable than the substrate. This caused a notable effect on the amount and distribution of $\mathrm{CaCO}_{3}$ in the substrate downstream. Cartridges 8 and 18 were most affected by the sand pac with the result that $\mathrm{CaCO}_{3}$ deposition occurred throughout most or all of the flow paths. This gave an opportunity to get quantitative data about the calcitel aragonite ratios across the zones of deposition.

The varying proportions of calcite and aragonite were easily recognized in thin sections. To quantify those proportions, channel samples were chipped from the epoxy-filled compacts and analyzed by $x$-ray diffractometry. Heights of the major calcite and aragonite diffraction peaks were compared with standards prepared from pure materials that were scanned similarly. The results (5) for 4 cartridges are 1 isted in Table 6 along with the positions of the channels made in the compacts.

Table 6: PROPORTIONS OF CALCITE AND ARAGONITE IN SELECTED DEPOSITION ZONES

\begin{tabular}{ccc} 
CARTRIDGE & $\frac{m m}{2}$ FROM EXIT FACE & $\frac{\text { CALCITE/ }}{\text { ARAGONITE }}$ \\
\hline 4 & $1-2.5$ & 0 \\
8 & $32-36$ & $0.85 \pm 0.15$ \\
8 & $22-26$ & $0.45 \pm 0.10$ \\
8 & $12-16$ & $0.015 \pm 01$ \\
8 & $1-2.5$ & Absent \\
18 & $27-33$ & $0.007 \pm .04$ \\
18 & $1-6$ & $0.03 \pm 02$ \\
19 & $0.5-4.5$ & $1.4 \pm 0.3$
\end{tabular}

A profile of the calcite/aragonite ratio vs position was provided from cartridge \#8 which is plotted in Fig 9. This profile shows that the calcite/aragonite proportions become completely

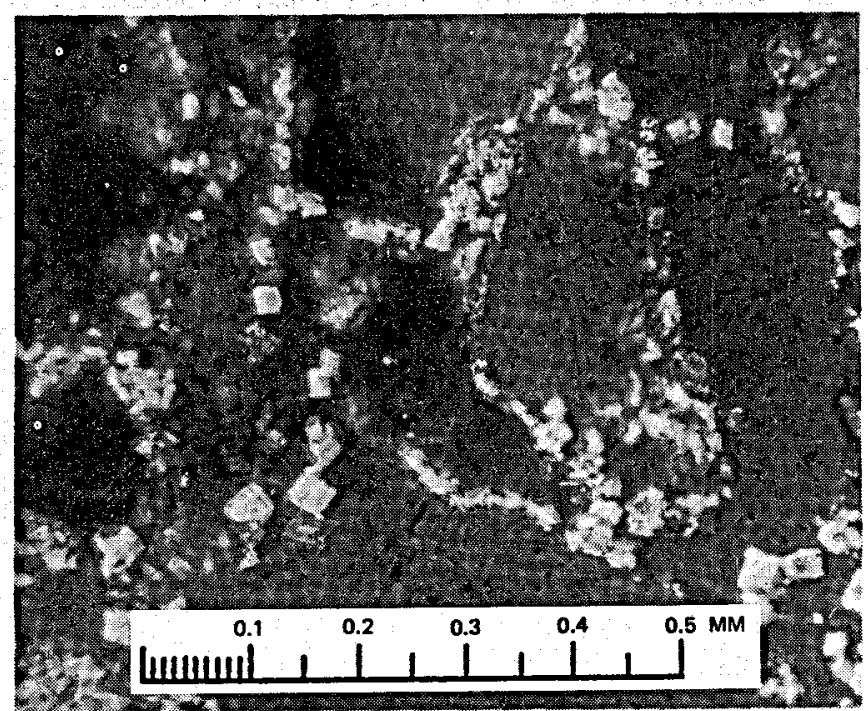

FIGURE 10a: Calcites decorating sand No.3 in cartridge No.13, 9.3 $\mathrm{mm}$ above the exit face. These rhombs are among the first $\mathrm{CaCO}_{3}$ to deposit along the flow path.

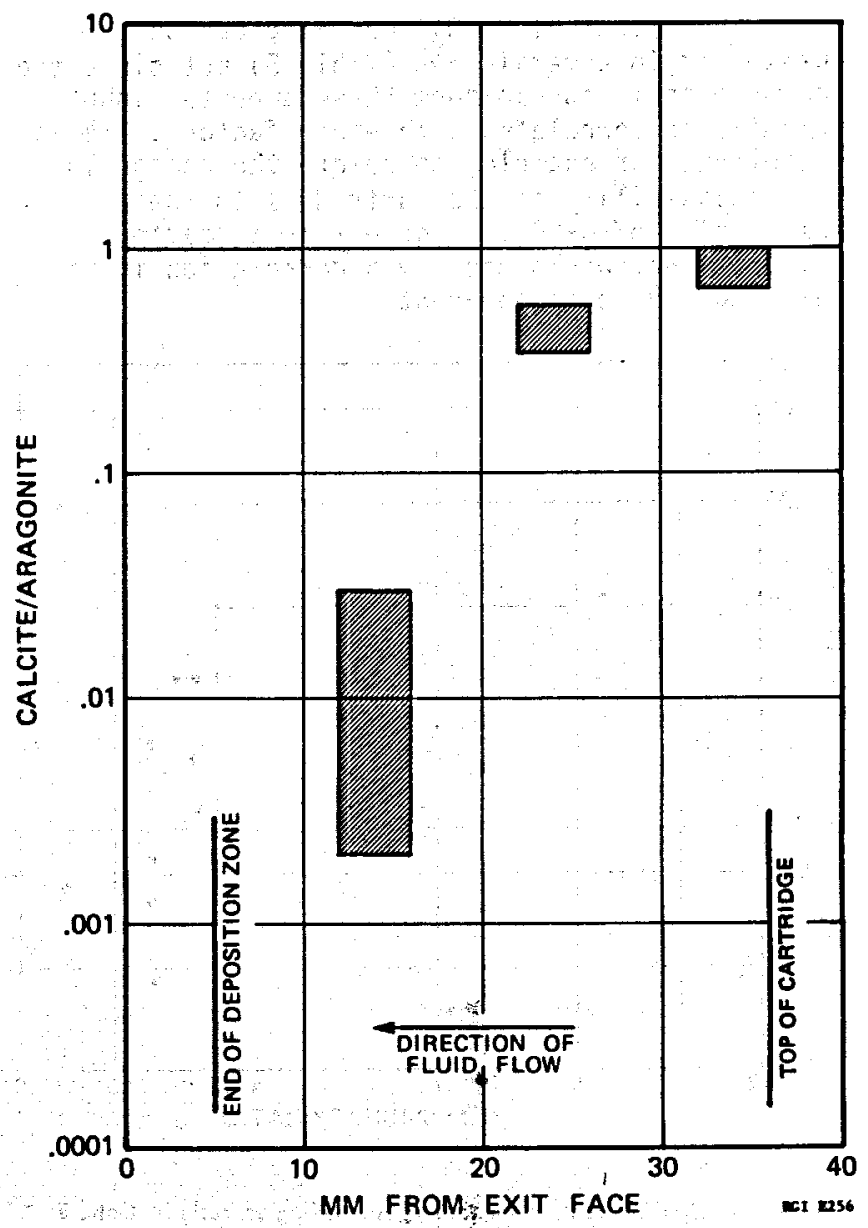

FIGURE 9: Proportions of calcite and aragonite across a deposition zone (cartridge No.8). Ratios are based on x-ray diffraction data.

aragonitic before the end of the deposition zone. This is the same result seen in thin sections where the deposition zone was too thin to sample for $x$-ray studies. For example, cartridge 13 received deposition over a zone less than $10 \mathrm{~mm}$ wide, with most of the deposition occurring in the last $3 \mathrm{~mm}$ of that zone. Figure 10 a shows calcite rhombs dominate in the upstream portion of the deposition zone while aragonite acicules (Fig. 10b) dominate in the lower portion.

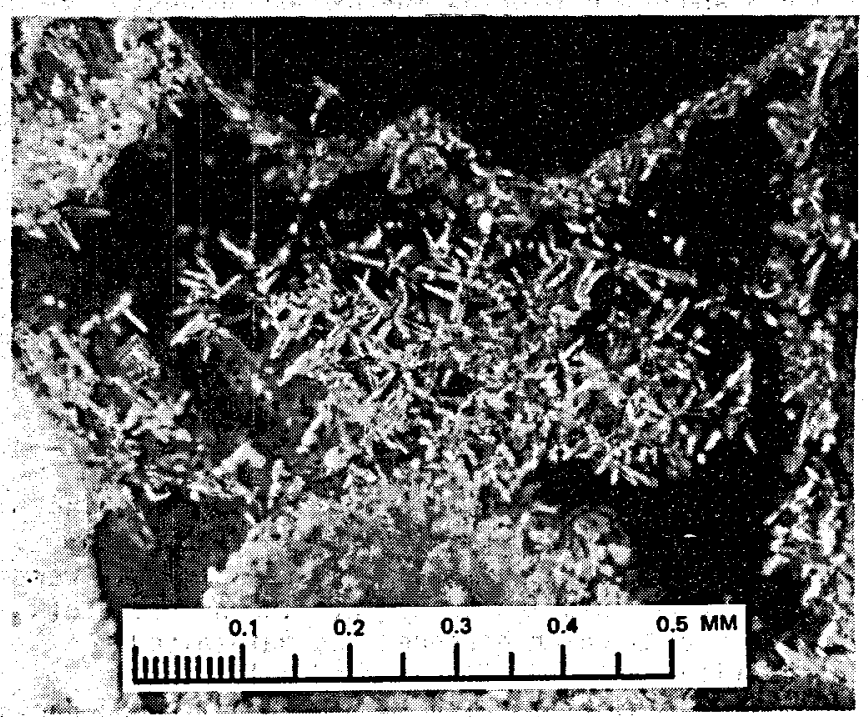

FIGURE 10b: Aragonites on sand No.3 in cartridge No. $13,0.7 \mathrm{~mm}$ above the exit face. These acicules are among the last $\mathrm{CaCO}_{3}$ to deposit along the flow path. 
The factors that determine which crystalline form is dominant concern initially the crystal nucleation event and subsequently involve the conditions of crystal growth. The nucleation and growth take place in a stagnant liquid boundary layer that interacts with the vapor composition by diffusion of components through a mobile liquid layer. The favorability of growth conditions depends on the relative concentrations of several dissolved components, not just simply $\mathrm{Ca}^{++}$and $\mathrm{CO}_{3}=$. The growth mechanisms for calcite and aragonite involve different sets of discreet events. The transitional character of the calcite/aragonite ratio reflects the differing availability of important components which nourish the growth of the polymorphs.

Density of $\mathrm{CaCO}_{3}$ crystals on the grains of substrate is, in some places, remarkable for the uniformity of its density. Except where crystals are crowded, they are often regularly spaced and of similar size. Furthermore, the uniformity of decoration around a single grain of substrate shows how remarkably well the stagnant boundary layer is separated from the active flow path. Figure 11 shows single crystals of calcite uniformly spaced around grains of sand S1.

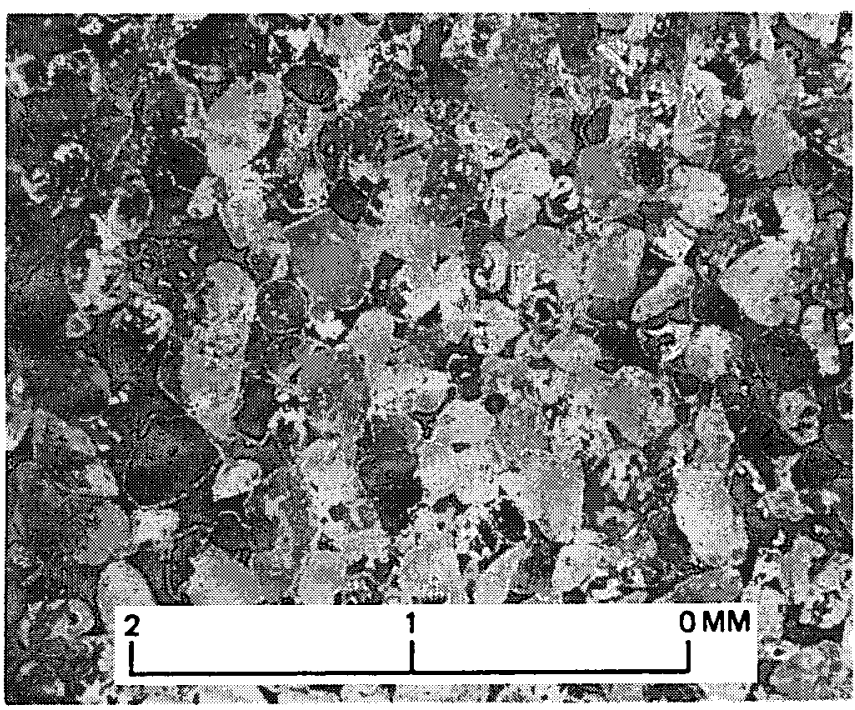

FIGURE 11: Cross-section throught the $\mathrm{CaCO}_{3}$ deposition zone in cartridge No.4, sand 1. Flow was from right to left and all deposition is calcite. Position of exit face is approximately at the left hand edge of the view. Note uniformity of calcite decorations on individual grains of substrate located at both ends of the zone.

Analogously, Figure 12 shows aragonite deposition on $3 \mathrm{~mm}$-diameter glass spheres next to flow channels in cartridge \#18. One can infer that these spheres have larae differences in the intensity of droplet impact across their surfaces hecause the surfaces of nearby spheres are so non-uniformly distant. Despite such inferred differences in surface stress and material flux

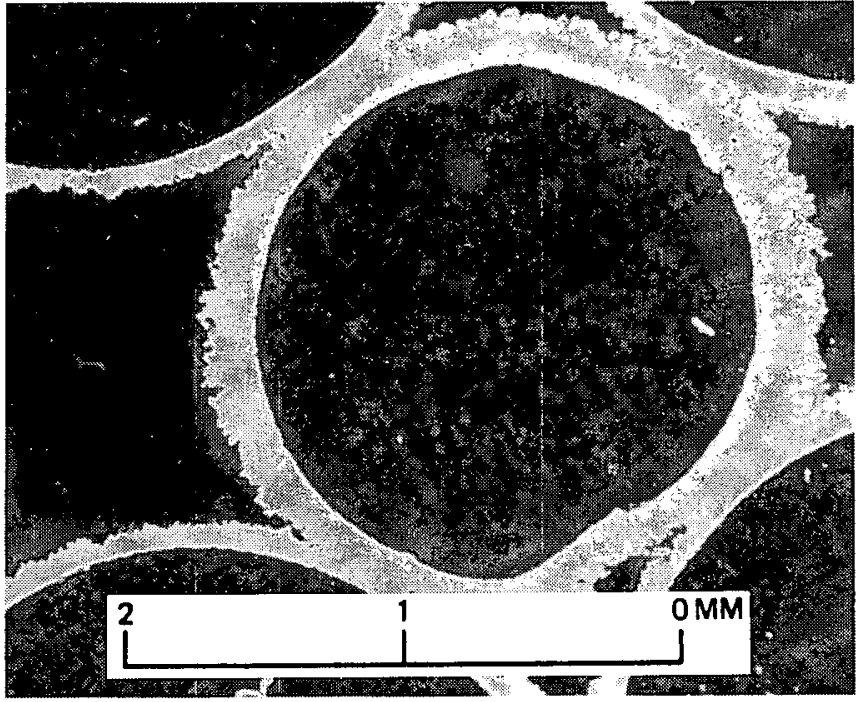

FIGURE 12: Cross-section through cartridge No.18, Glass 1, showing aragonite deposition. Note uniformity of rind thickness around single spheres. Different apparent thickness on adjacent spheres is a geometrical effect due to the plane of sectioning, cutting the spheres in different relative positions. Intact spheres are all $3.0 \mathrm{~mm}$ in diameter.

(grams of fluid per. second per square $\mathrm{mm}$ of sphere) the deposit is not only uniform throughout that portion of one pore which the sphere bounds, but also similar thicknesses are present in adjacent pores which contact the same sphere.

This result also shows the contrast between crystal growth by ionic reactions and scale buildup by accumulation of suspended solid particles. Significantly, throughout these studies there were no indications that scale deposition took place when solid materials, perhaps formed in the homogeneous liquid, adhered to substrates against which they impacted. This observation can be made more concrete. Particles of $\mathrm{CaCO}_{3}$ cannot develop except on a stationary surface that is proximate to the zone of flashing. Even if suspended particles, present before flashing, were used as $\mathrm{CaCO}_{3}$ crystal nuclei, they cannot grow perceptibly during the brief times (fractional seconds) they are immersed in conditions which favor such growth. Thus, the presence of $\mathrm{CaCO}_{3}$ particles suspended in the fluid remote from the zone of the flashing/deposition would demonstrate their detachment/erosion from surfaces upstream.

Across the zone of $\mathrm{CaCO}_{3}$ deposition, and in the direction of fluid flow, the number of crystals per unit volume (or per unit area of substrate grain) increases, sometimes to the point of closing the porosity, and then the density decreases as the exit.face is approached (Fig. 13). Most often the polymorph which develops in the region near the exit face is aragonite. The growth of individual aragonites apparently is exceedingly fast since (immature) crystals smaller than the grade size are not abundant.

Closure of porosity by aragonite occurs through an intense development of individual crystals that are similar in size and shape to the crystals in sparser populations (Figure 13). This arrangement appears to have considerable porosity 


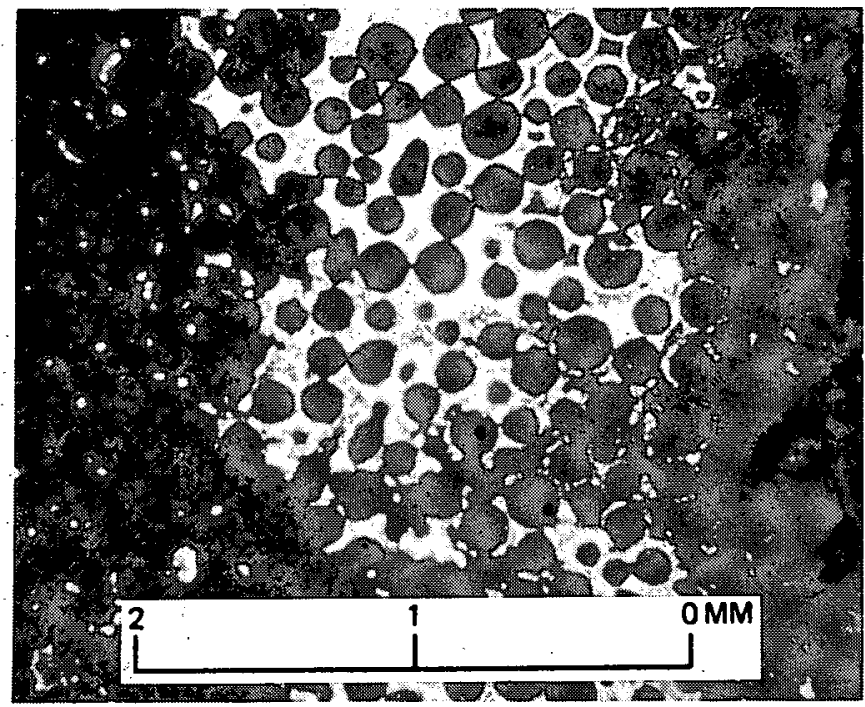

FIGURE 13: Aragonite deposition in cartridge No.19, Glass 2. Fluid flow was from left to right. Position of exit face is near right edge of view. Closure of permeability is nearly complete.

because the crystals are acicular and (apparently) randomly arrayed. However, the dimensions are so small that virtually all the non-crystall ine space is comprised of boundary layer so that bulk flow would encounter very high resistance.

It is important to note that the amount of deposition diminishes near the exit face in spite of (1) an increased degree of flashing which (upstream) was related to an increasing potential for crystal growth, and (2) the generally low chemical efficiences for removing $\mathrm{Ca}$ as indicated by analyses of the liquid discharge.

Two rock samples were mounted in the experimental cartridges and carried through the same procedures as were the granular substrates. One rock was too impermeable to yield data. The other, in cartridge \#25, with an initial one-phase permeability of about 10 millidarcys, transmitted about $140 \mathrm{~kg}$ of fluid in 9.4 hours of exposure.

The final 1-phase permeability was $2-1 / 2$ times greater than the initial, but the final 2 -phase transmissibility was about $25 \%$ less than the initial. Chemical analysis of the transmitted liquid implied the pickup of 0.475 grams of $\mathrm{Ca}$ $\left(1.18\right.$ of $\left.\mathrm{CaCO}_{3}\right)$. A weight loss of 2.0 grams was measured for the cartridge assembly. A thin section showed new $\mathrm{CaCO}_{3}$ (as Calcite) only on the exit face of the rock sample. This rock contains natural calcite cement and the data suggest some redistribution of components. Yet, redistribution was not noticed in the thin section.

\section{INTERPRETATION OF RESULTS}

The principal goal of this section is to relate the chemical events to the physical conditions inside the cartridge and to the fluid which flashes in them. The process does not follow an equilibrium path, hence the discussion must al so describe the departure from equilibrium and the reasons why such an outcome occurs.

\section{Transition from 1-Phase to 2-Phase flow}

The chemical events of $\mathrm{CaCO}_{3}$ deposition are commonly regarded as responding to the flashing process with negligible delay. My experiments show that the response is not instantaneous. That is, the places in the cannisters where 2-phase fluid began to develop appear to be substantially up-flow from the places where $\mathrm{CaCO}_{3}$ began to deposit. This fact is important to subsequent sections, which describe. how non-equilibrium is sustained, and it is wortinwile to elaborate on the hydrodynamic evidence for it. The chemical evidence for non-equl ibrium will be considered separately.

Since flashing and deposition are related as cause and effect, the uppermost $\mathrm{CaCO}_{3}$ deposition marks the lowermost possible position for the transition from 1-phase to 2-phase flow. For the sake of a simple limiting calculation one may assume that the deposition response is prompt. In this geometric model: the pressure gradients in the 1-phase segments would be inversely proportional to the lengths of the segments, adjusted for input pressure, as in (T1)

$$
g_{1}=\frac{I-F}{(\ell-d)}
$$

Where $g_{1}=$ pressure gradient in the 1-phase segment of path

$F=$ flash point pressure for the liquid

$I$ : input pressure

$d=$ length of 2 -phase segment (see Table 5 )

$\ell=$ total length of compact

Results for (T1) are listed in Table 7 , col. 3 as 91-geometric, alongside results for a dynamic model, described next.

The length of the 1-phase flow path al so can be calculated from an empirical formula for non-Darcian flow (6). The formula involves two terms for the resistance of fluid movement. One is normal Darcian resistance which is proportional to fluid speed raised to the first power. The second term involves fluid speed raised to the second power as shown in (T2).

$$
\begin{aligned}
g=\left(\frac{20.2}{k}\right)\left(\frac{m \ell}{v}\right)+\left(\frac{1142}{k \cdot 933}\right)\left(\frac{m \ell}{v}\right)^{2} \\
m=\text { mass flow rate }(\mathrm{kg} / \mathrm{sec}) \\
1=\text { length of compact }(\mathrm{m}) \\
v=\text { volume of compact }\left(\mathrm{cm}^{3}\right) \\
k=\text { permeability (darcys) }
\end{aligned}
$$

Results for (T2) are listed in Table 7 , col. 4, in terms of the pressure gradient. The Darcian component of the gradient $g_{1}-D$ is 1 isted separately to show that, under these experimental conditions, the second term (with speed 2 ) is dominant. The values, $9_{1}$-dynamic, (column 4), are to be compared with $g_{1}$-geometric values $(\mathrm{col} .3)$.

In all cases, the dynamic model predicts a steeper pressure gradient than does the geometric 
Table 7: TRANSITION POINTS FOR 1-PHASE TO 2-PHASE FLOW

\begin{tabular}{|c|c|c|c|c|c|c|c|c|c|}
\hline SUBS. & CART. & $\begin{array}{l}\text { INLET } \\
\text { GAUGE } \\
\text { PRESSURE }\end{array}$ & $\begin{array}{l}\text { INITIAL } \\
\text { FLOW } \\
\text { RATE }\end{array}$ & \multicolumn{3}{|c|}{$\begin{array}{l}\text { 1-PHASE GRADIENTS } \\
\mathrm{kg} / \mathrm{cm}^{2} \text { per } \mathrm{cm}\end{array}$} & \multicolumn{2}{|c|}{$\begin{array}{c}\text { 1-PHASE PATH LENGTH } \\
\mathrm{mm}\end{array}$} & $\begin{array}{l}\text { CALCULATED } \\
\text { FLOW } \\
\text { RATE }\end{array}$ \\
\hline & & $\begin{array}{c}\mathrm{kg} / \mathrm{cm}^{2} \\
1\end{array}$ & $\begin{array}{c}g / \mathrm{sec} \\
2 \\
\end{array}$ & $\begin{array}{c}\text { geometric } \\
3 \\
\end{array}$ & $\begin{array}{c}\text { dynamic } \\
4 \\
\end{array}$ & $\begin{array}{c}\text { Darcian } \\
\underline{5} \\
\end{array}$ & $\begin{array}{c}(1-d)-\text { geom } \\
6 \\
\end{array}$ & $\begin{array}{c}(1-d)-d y n \\
7 \\
\end{array}$ & $\begin{array}{c}\mathrm{g} / \mathrm{sec} \\
8\end{array}$ \\
\hline $\mathrm{S1}$ & $\begin{array}{r}3 \\
4 \\
6 \\
20\end{array}$ & $\begin{array}{l}8.93 \\
9.42 \\
9.14 \\
6.47\end{array}$ & $\begin{array}{r}54 \\
254 \\
213 \\
200\end{array}$ & $\begin{array}{r}1 . \\
1.10 \\
0.95 \\
.20\end{array}$ & $\begin{array}{l}.26 \\
3.07 \\
2.79 \\
1.36\end{array}$ & $\begin{array}{l}.07 \\
.22 \\
.25 \\
.12\end{array}$ & $\begin{array}{r}- \\
32 \\
34 \\
28\end{array}$ & $\begin{array}{r}-\overline{5} \\
11.5 \\
11.6 \\
4.2\end{array}$ & $\begin{array}{r}- \\
148 \\
120 \\
72\end{array}$ \\
\hline$S 2$ & 10 & 10.4 & 358 & 1.43 & 3.76 & .20 & 31.5 & 12.0 & 217 \\
\hline 53 & $\begin{array}{l}13 \\
14\end{array}$ & $\begin{aligned} 10.4 \\
9.56\end{aligned}$ & $\begin{array}{l}209 \\
247\end{array}$ & $\begin{array}{l}2.05 \\
1.16\end{array}$ & $\begin{array}{l}2.50 \\
3.61\end{array}$ & $\begin{array}{l}.23 \\
.30\end{array}$ & $\begin{array}{r}22 \\
31.5\end{array}$ & $\begin{array}{l}18.0 \\
10.1\end{array}$ & $\begin{array}{l}188 \\
136\end{array}$ \\
\hline 54 & $\begin{array}{l}21 \\
22\end{array}$ & $\begin{array}{l}7.17 \\
9.70\end{array}$ & $\begin{array}{l}117 \\
222\end{array}$ & $\begin{array}{r}.53 \\
1.19\end{array}$ & $\begin{array}{l}1.56 \\
7.17\end{array}$ & $\begin{array}{l}.25 \\
.67\end{array}$ & $\begin{array}{r}24 \\
32.6\end{array}$ & $\begin{array}{l}8.1 \\
5.3\end{array}$ & $\begin{array}{l}64 \\
84\end{array}$ \\
\hline G1 & 18 & 10.3 & 199 & - & .052 & .004 & - & - & - \\
\hline G2 & $\begin{array}{r}8 \\
19\end{array}$ & $\begin{array}{l}10.4 \\
7.45 *\end{array}$ & $\begin{array}{r}46.3 \\
269\end{array}$ & $0.4 \overline{6}^{-}$ & $\begin{array}{r}.10 \\
1.99\end{array}$ & $\begin{array}{l}.03 \\
.14\end{array}$ & $\begin{array}{r}2 \\
33.5\end{array}$ & $7 . \overline{8}$ & 125 \\
\hline$M 1$ & $\begin{array}{r}1 \\
17\end{array}$ & $\begin{array}{l}9.00 \\
7.03\end{array}$ & $\begin{array}{l}418 \\
314\end{array}$ & $\begin{array}{l}0.84 \\
0.37\end{array}$ & $\begin{array}{l}2.08 \\
1.09\end{array}$ & $\begin{array}{l}.09 \\
.06\end{array}$ & 31 & $\begin{array}{l}14.9 \\
10.4\end{array}$ & $\begin{array}{l}262 \\
178\end{array}$ \\
\hline M2 & $\begin{array}{r}2 \\
7 \\
15\end{array}$ & $\begin{array}{r}9.42 \\
- \\
-\end{array}$ & $\begin{array}{r}422 \\
\star \\
\star\end{array}$ & $\begin{array}{r}1.35 \\
- \\
-\end{array}$ & $\begin{array}{r}.75 \\
- \\
-\end{array}$ & $\begin{array}{r}.03 \\
- \\
-\end{array}$ & $\begin{array}{r}26 \\
- \\
-\end{array}$ & $\begin{array}{l}- \\
-\end{array}$ & $\begin{array}{l}- \\
-\end{array}$ \\
\hline M3 & $\begin{array}{r}9 \\
16\end{array}$ & $\begin{array}{l}6.47 \\
10.3\end{array}$ & $\begin{array}{l}216 \\
594\end{array}$ & $\begin{array}{l}0.22 \\
1.69\end{array}$ & $\begin{array}{r}.74 \\
4.54\end{array}$ & $\begin{array}{l}.06 \\
.14\end{array}$ & $\begin{array}{l}26 \\
26\end{array}$ & $\begin{array}{l}7.7 \\
9.7\end{array}$ & $\begin{array}{l}113 \\
359\end{array}$ \\
\hline
\end{tabular}

model, implying that the onset of flashing accurs upstream of the $\mathrm{CaCO}_{3}$ deposition zone. The locations of flash points, based on this dynamic model, are 1 isted in col. 7 alongside the locations of the uppermost $\mathrm{CaCO}_{3}$ crystals observed in thin sections, col. 6. The mismatches among these value pairs reflect the delay in chemical response to the onset of flashing.

The accuracy of the conclusion above is sensitive to both the relevance of the Saucier model (6) and to the accuracy of the field data for mass flow rate. Because the Saucier model was developed and calibrated with materials that spanned the range of permeabilities for materials used in this study the relevance appears clear.

The accuracy in measuring mass flow rate is assessed in the following way. A smaller mass flow rate would have the effect, in the model, of displacing the point of initial flashing down flow. Thus, if the true rates were sufficiently less than measured, the deposition and flash point might coincide. One can calculate a flow rate which, in the model, would bring the flash point and the uppermost deposition into coincidence. This was done and the results are shown in Table $7, \mathrm{col} .8$. Those values, compared to measured counterparts in col. 2, are smaller by about $40 \%$, implying that measurement errors of that proportion must be postulated to invalidate the conclusion about non-coincidence. Since the flow rates were obtained by a timed collection of weighed fluid, such a large error is not tenable.

\section{Pathways and Non-equilibrium for Flashing}

Departures from equilibrium are generally awkward to describe with numerical models and in this case the dynamics of the process and its multi-dimensionality would make such an effort particularly difficult. Thus, a graphical method will be used in which the reactions are described as pathways across a field of temperature and pressure. Specifically, the pressure of $\mathrm{CO}_{2}(\mathrm{~g})$ is used because that permits one to construct several response surface maps that describe significant aspects of carbonate chemistry that are important to the depositions of $\mathrm{CaCO}_{3} .{ }^{\circ}$ Figure 14 shows the results of this approach and examination of it should be coordinated with the following discussion.

The field of Temperature vs $\mathrm{CO}_{2}$ 'Pressure is useful here because a line connecting two points in it can be considered as a path (that may be) taken as the fluid/liquid changes. from one condition to another. Of course, not all paths that might be drawn in the field can correspond to paths naturally taken by real systems. Furthermore, real systems are constrained within boundaries. For the case of the flashing geo- 


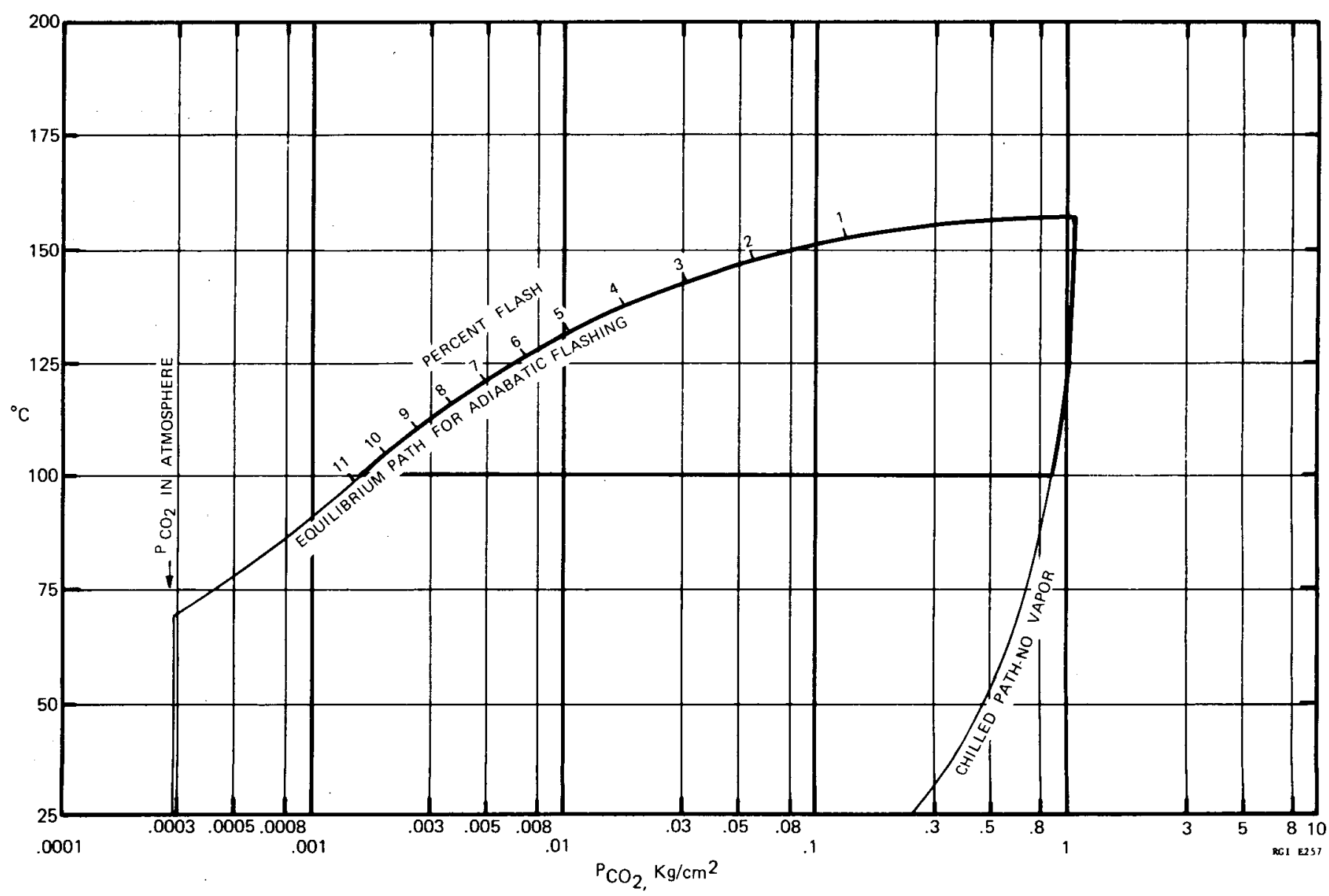

FIGURE 14: Pathway diagram for geothermal liquid in field of Temperature and $\mathrm{CO}_{2}$ Pressure. Boundaries for possible paths are given by adiabatic flashing (upper), forced cooling (lower right), and atmospheric content of $\mathrm{CO}_{2}$ (left). Pathways across the bounded area are possible; they can be adiadatic. Such cases involve disequilibrium of $\mathrm{CO}_{2}$ vis-a-vis liquid and vapor. Initial conditions for experiments were $158^{\circ}, 500 \mathrm{ppm} \mathrm{HCO}_{3}, \mathrm{PCO}_{2}=1.13 \mathrm{~kg} / \mathrm{cm}^{2}$.

thermal liquid in this experiment, two boundaries in the Temp- $\mathrm{PCO}_{2}$ field are the path for an adiabatic equilibrium expansion and a path for cooling without development of a vapor phase. These are both superimposed in Figures 14-18. The method for calculating them is given in Appendix $c$. Additionally, the $100^{\circ} 1$ ine represents a path boundary for the liquid while it is within the cartridges.

In principle, all the area within those boundaries is available to real processes at the start of an expansion-cooling process.

Furthermore, the real process actually achieved by the system must be describable by some continuous line across the map that stays within the boundaries. This line never, can have a negative slope relative to the Temp-CO2 axis; such a slope constitutes violation of the First Law of thermodynamics. Importantly, these response surface maps concern only the liquid phases that are transiently residual during the process. Further, al the area of Figures $15,16,17$ and just the pathways shown in Figures 14 and 18 are specific for the content of $\mathrm{HCO}_{3}{ }^{-}$concentration being $500 \mathrm{ppm}$ before flash.

The calculated position of the upper boundary is based on the $\mathrm{CO}_{2}$ partial pressure in the vapor being equal to the calculable Henry's Law pressure for the liquid, the latter being dependent on the concentration of $\mathrm{CO}_{2}(\mathrm{aq})$.
Non-equality of these two pressures is one definition of non-equilibrium for this system and more is said about that in Appendix $C$. Thus, drawing a line across the response surface (except the boundary lines described abovel implies al so a non-equality for the $\mathrm{CO}_{2}$ pressures between the vapor and 1 iquid phases.

With time, which normally involves more cooling, all non-equilibrium paths will, at their lower ends, extend toward the equilibrium curve which is their upper limit. Thus, for the quick events of flashing it is the middle parts of the path that are most interesting. The objective of the next section can now be phrased as, "How far do actual flashing processes, represented by 1 ines on the response surface map, pass below the equilibrium path?"

The method used here applies to situations in which $\mathrm{pH}$ is controlled by the carbonate equilibria and the $\mathrm{Ca}$ concentration is small compared to the $\mathrm{HCO}_{3}-\mathrm{CO}_{3}$ couple.

\section{Response Surface Maps}

Response surface maps (7) (Figures 15, 16, 17) are graphs in which isopleths of a (dependent) variable are drawn between axes which represent two independent variables. The isopleths and the interpolations between them show values the dependent variable would have at coordinate points 


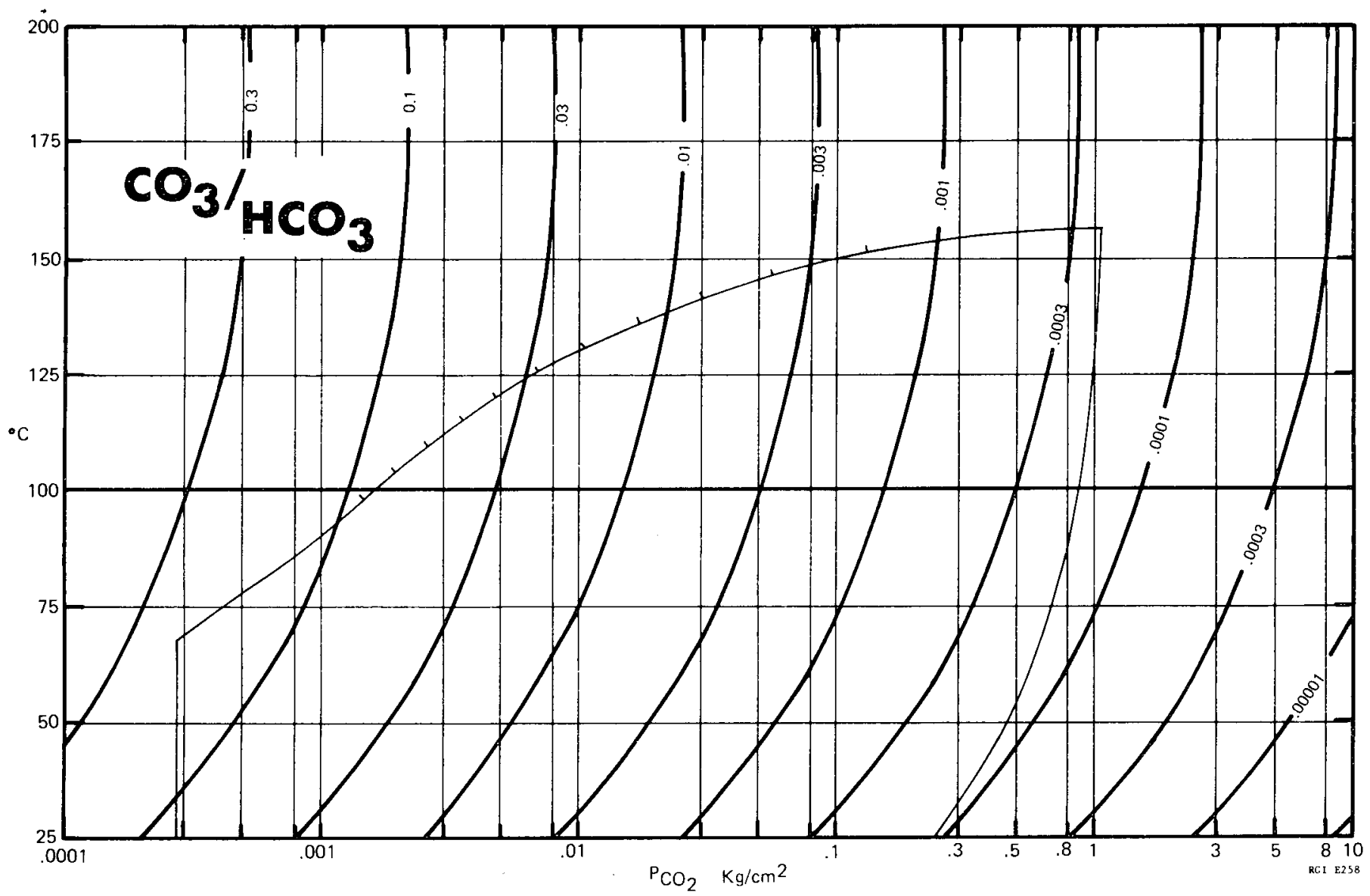

FIGURE 15: Response surface; ratio of $\mathrm{CO}_{3} / \mathrm{HCO}_{3}$ in a field of Temperature and $\mathrm{CO}_{2}$ Pressure based on $\mathrm{HCO}_{3}+2 \mathrm{CO}_{3}=500 \mathrm{ppm}$ and activity coefficients $=1$. Pathway boundaries for experimental fluid are superimposed.

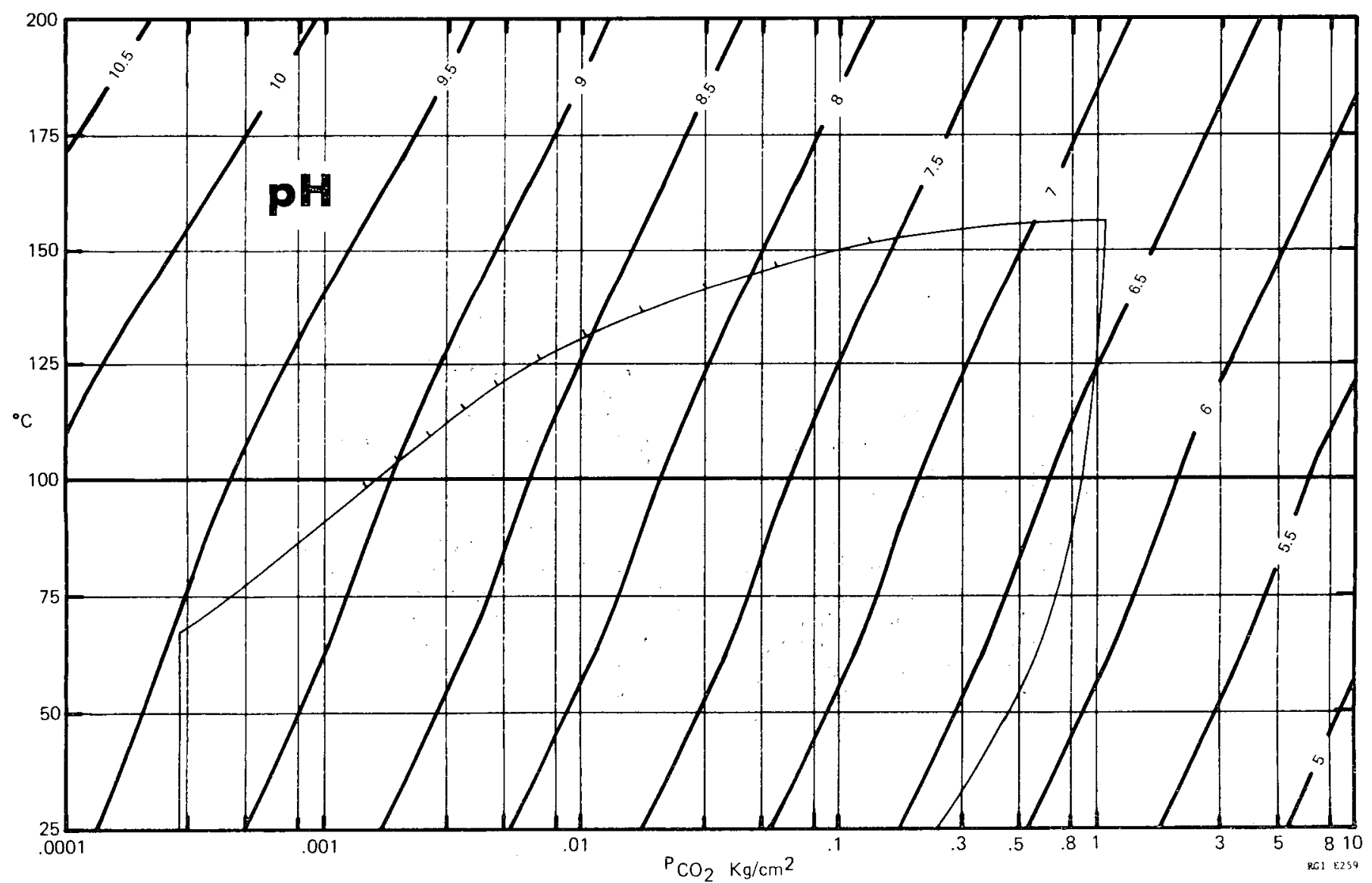

FIGURE 16: Response surface; $\mathrm{pH}$ in a field of Temperature and $\mathrm{CO}_{2}$ Pressure based on $\mathrm{HCO}_{3}+2 \mathrm{CO}_{3}=500$ ppm and activity coefficients $=1$. Pathway boundaries for experimental fluid are superimposed. 


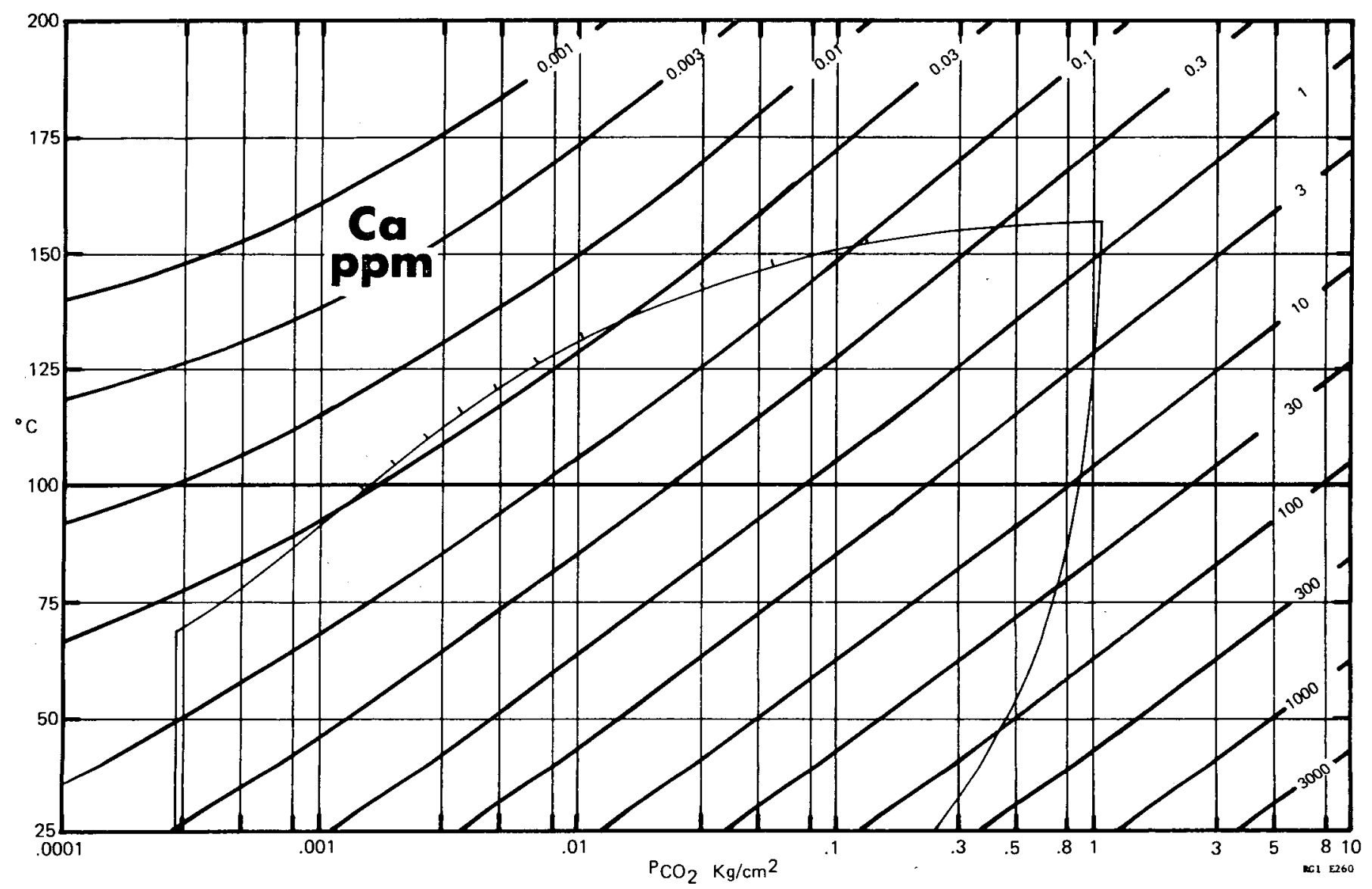

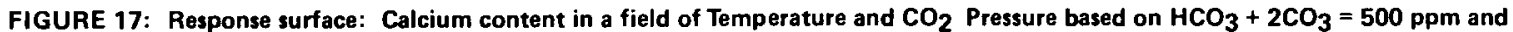
activity coefficients = 1, (see appendix B). Pathway boundaries for experimental fluid are superimposed.

identified by sets of values for the independent (field) Darameters. The isopleths describe a surface in the 3 -dimensional space of all the variables and may be read like the contours on a topographic map. As with a topographic map, the gradient of the response surface at any point is indicated by the relative closeness of the isopleths. A non-linear functional relationship between the dependent and independent variables is indicated by unequal spacings of the isopleths across the field. A joint functional dependence is indicated by isopleths inclined to the axes.

Three response surface maps are useful for interpreting the results of this study and they must be specifically constructed. Appendix A shows how the maps are derived from mathematico-chemical equations of carbonate equilibria, and Appendix B describes the constructions. In this development a slightly different mathematical development is used compared to usual methods in order to avoid certain inconsistencies that are noted in Appendix A. The success of this approach is indicated by the $\mathrm{pH}$ response surface (Figure 16) which displays calculated increases of pH for East Mesa fluids that are in concert with observed increases. This result was achieved without making presumptions about $\mathrm{pH}$ or $\mathrm{CO}_{3}=/ \mathrm{HCO}_{3}$ - ratio anywhere along the flashing path.

\section{Tracks of Real Pathways}

Figure 18 is similar to Fig. 14 but includes. al so expectations about $\mathrm{CaCO}_{3}$ deposition. The dashed lines in Fiqure 18 are based on the $\mathrm{Ca}$ isopleths from Fiqure 17 and show the (maximum) fraction of the Ca available initially which would be deposited by any pathway/process that originated on the zero efficiency line. Actual chemical efficiencies are available in Table 5 and most are small compared to the "equilibrium expectation lines" of Figure 18.

Note that the equilibrium path implies that $80 \%$ of the Ca initially present will be deposited before the system experiences $1 \%$ of flash, whereas most efficiencies in Table 5 are in the range of 10 to $30 \%$. It is furthermore interesting that, between the $3 \%$ and $11 \%$ stages of flash, the equilibrium path has a trend nearly parallel to the $\mathrm{Ca}$ isopleths. This implies that essentially all the $\mathrm{Ca}$ which can be deposited would be deposited in an equilibrium process before $3 \%$ of flashing has occurred. In the field experiments only a few of the cartridges emitted fluid that had not flashed to most of its potential of about about $11 \%$. It is not tenable to suspect that any flashing was so small as $3 \%$. Thus, the actual pathways would appear to have seldom approached nearer to the equilibrium path than the 0.3 deposition line that appears in Figure 18 .

Two other observations mentioned earlier are especially relevant here: (1) the relatively steep calculated pressure gradients for the 2-phase portion of the fluid path indicated that the actual position of the 1- to 2-phase transition was located substantially upstream of the place where the first crystals of $\mathrm{CaCO}_{3}$ could be found. 


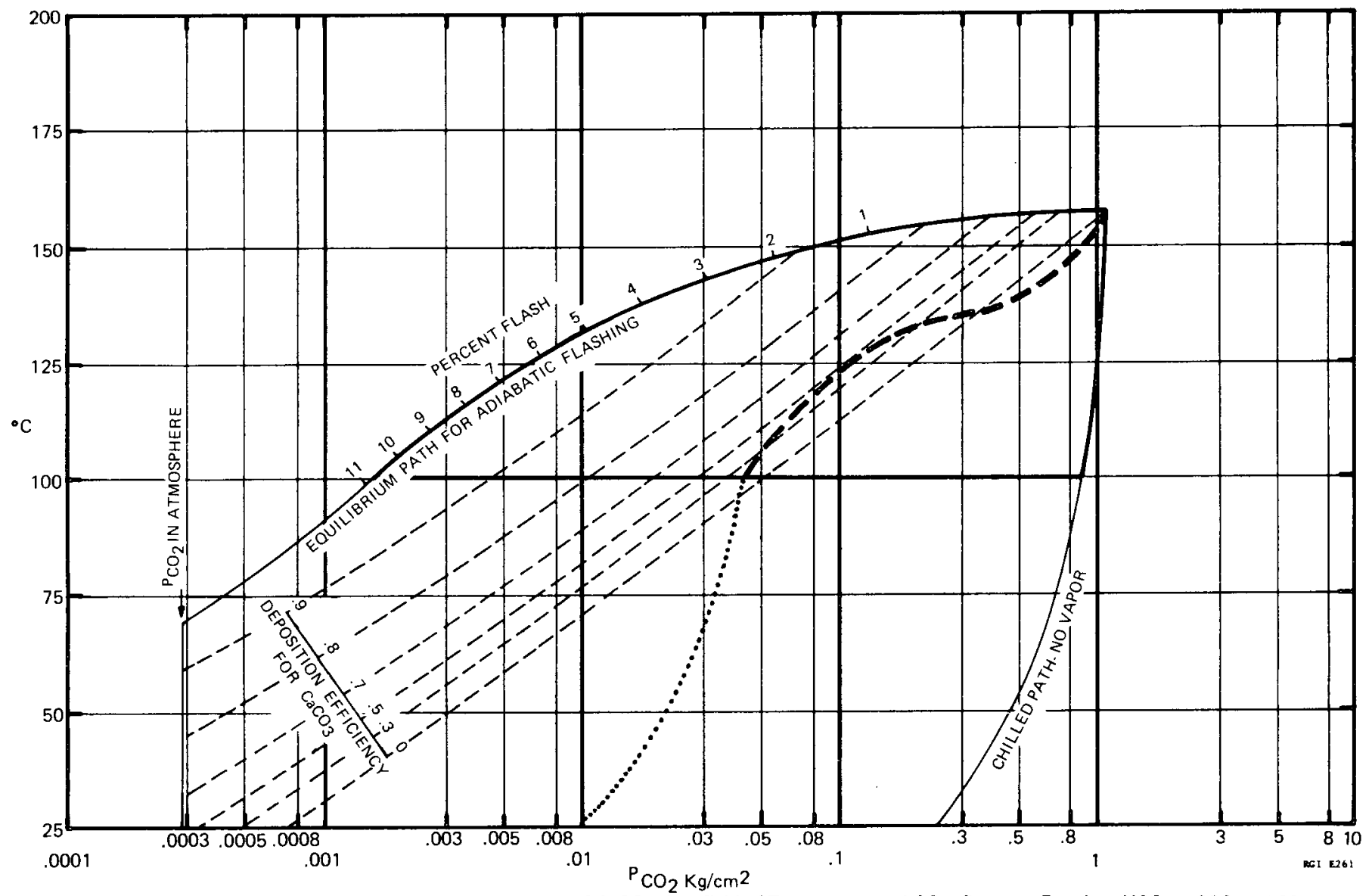

FIGURE 18: Pathway diagram and efficiencies for deposition of $\mathrm{CaCO}_{3}$ in a field of Temperature and $\mathrm{CO}_{2} \mathrm{Pressure} \mathrm{Based} \mathrm{on} \mathrm{HCO}+2 \mathrm{CO} \mathrm{O}_{3}=500 \mathrm{ppm}$.

Efficiencies are based on Fig. 17. Initial conditions for experimental fluid are $500 \mathrm{ppm} \mathrm{HCO}_{3}, \mathrm{PCO}_{2}=1.13 \mathrm{Kg} / \mathrm{cm} 2,158^{\circ}, \mathrm{Ca}=6.3 \mathrm{ppm}$. The heavy dashed line shows a nominal path for liquid flashing in the porous substrates used for this study (see text). The dotted extension shows cooling of the flashed liquid without further loss of $\mathrm{CO}_{2}(\mathrm{aq})$.

If one accepts for the moment that the thermodynamic driving force for $\mathrm{CaCO}_{3}$ deposition builds up as a property of the fluid in strict timing with the degree of flashing, then the actual position of the $\mathrm{CaCO}_{3}$ deposition would represent also the time delay between that buildup and the response to it of ions which add to the growing crystals. Actually, the situation is more complex because in the chain of real events, the buildup of the thermodynamic potential for $\mathrm{CaCO}_{3}$ deposition is preceded by the exhalation of $\mathrm{CO}_{2}$ from the liquid. Accordingly, the buildup of the thermodynamic driving force lags the expansion of flashing because the discrete events of $\mathrm{CO}_{2}$ transfer between phases al so take finite amounts of time that must precede the ionic events of crystal growth.

Within the liquid boundary layer which overlies the substrate grains and in which the srystal growth reactions occur, $\mathrm{CaCO}_{3}$ deposition will have significant thermodynamic driving force only where the $\mathrm{CO}_{2}(\mathrm{aq})$ has been depleted.

This depletion involves the structure of the liquid zones near the substrate surface.

Specifically, the immobile boundary layer does not reach equilibrium with the vapor nearest it. Two factors operate in the mobile liquid layer which preserve the disequilibrium at a stationary location in the substrate. The mobile layer provides a barrier for the normal diffusion of $\mathrm{CO}_{2}$ between the vapor and the immobile layer. In effect, the $\mathrm{CO}_{2}(\mathrm{aq})$ at a location in the immobile layer is in "equilibrium" with the $\mathrm{CO}_{2}(\mathrm{~g})$ in vapor which is some distance upstream. Since the mobile liquid layer comes from upstream locations which involve larger concentrations of $\mathrm{CO}_{2}(\mathrm{aq})$ the concentration gradient in the mobile layer will be non-linear for $\mathrm{CO}_{2}(\mathrm{aq})$, moving out of the boundary layers. This effect is shown in Figure 19.

The description above has a counterpart in the course of the path near the points of origin shown in Figs. 14-18. Specifically, with which boundary line is the actual path more nearly tangent? It is suggested here that the exhalation of $\mathrm{CO}_{2}$ is relatively difficult when the degree of flash is small and when the Henry's Law pressure of $\mathrm{CO}_{2}$ is small compared to the vapor pressure of the $\mathrm{H}_{2} \mathrm{O}$ : This prediction can be based roughly on the concept that when the area of the $1 \mathrm{iquid}$ vapor interface i.s smaller, the diffusion distances for the $\mathrm{CO}_{2}(\mathrm{aq})$ to a free surface are longer. Consistent with that, the path would initially trend nearer a tangent with the boundary on the right part of the expansion field and, briefly the liquid might be slightly undersaturated. Such a path is shown in Fig. 18. This surmise applies well at East Mesa where the water vapor pressure is several times as large as the Henry's Law pressure of $\mathrm{CO}_{2}(\mathrm{aq})$. However, in other waters the relative pressures may be reversed, in which cases the initial part of the actual expansion path may trend closer to the equilibrium path, yielding instant onset of supersaturation. 
FLUID SPEEDS IN THE BOUNDARY LAYERS

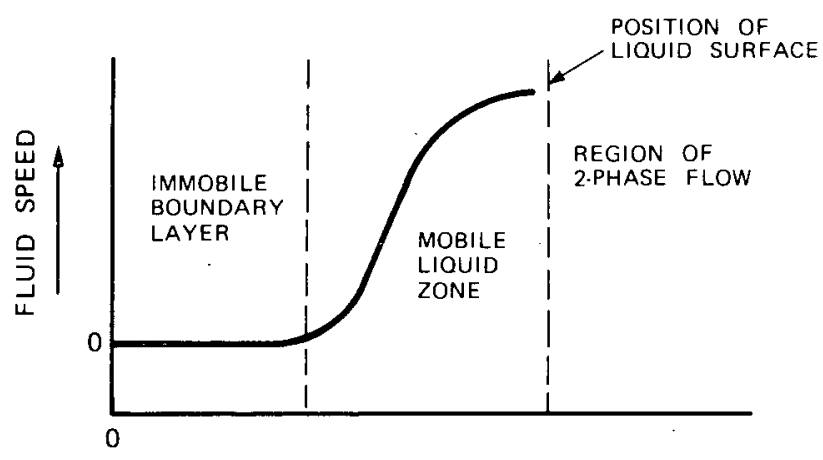

(B) $\mathrm{PCO}_{2}$ in THE BOUNDARY LAYERS

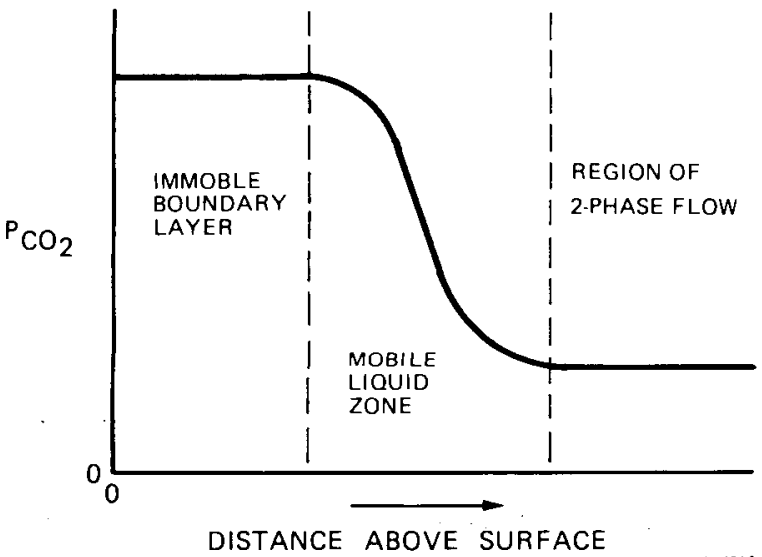

FIGURE 19: Steady-State disequilibrium of $\mathrm{PCO}_{2}$ during flashing in the vicinity of a substrate. $\mathrm{PCO}_{2}$ implies the calculable Henry's Law pressure in the liquid zones and the $\mathrm{CO}_{2}(\mathrm{~g})$ partial pressure in the region of 2-phase flow. Continuous arrival of mobile liquid from upstream maintains a high $\mathrm{PCO}_{2}$ in the immobile layer, compared to local vapor.

2) The absence of much $\mathrm{CaCO}_{3}$ deposition near the exit faces might be suggested as being due either to a thinning of the immobile liquid boundary 1 ayer, on account of the high fluid speeds there, or to an absence of thermodynamic driving force for the reaction there. The latter seems more in line with other evidence.

Any postulated thinning of the immobile boundary layer apparently is not significant. No effect can be noticed in cartridge 18 (Figure 12) where the degree of flash and size of pores would be expected to yield the maximum amount of buffeting compared to other test cartridges. For example, if thinning were to take place, its effect would yield a pattern of irregularity on individual grains of substrate. Yet, grains in the near-exit positions that are less heavily decorated with $\mathrm{CaCO}_{3}$ than their upstream counterparts, never-the-less show uniformity in the thickness of deposits on their perimeters.

Similarly, plucking of $\mathrm{CaCO}_{3}$ crystals from the near-exit grains by buffeting effects would lead to non-uniform decoration and can be discounted with the same evidence.
The argument about slow $\mathrm{CaCO}_{3}$ deposition being due to tardy exhalation of $\mathrm{CO}_{2}$, as used for the earliest part of the flashing, cannot be applied to the near-exit phenomena since relatively heavy deposition occurs just upstream. Furthermore, that heavy deposition often consumed only $20 \%$ or so of the ultimate deposition potential. Thus the concept of a locally inadequate thermodynamic driving force becomes appealing to explain the non-deposition at exit faces. This is equivalent to the flashing path recrossing the $\mathrm{Ca}$ isopleths (of the response surface in the portion of the path near the exit temperature), or passing parallel to them. The scenario of "recrossing" implies that ionic events of crystal growth could not keep pace with the changing thermodynamic potential for growth. The scenario of "parallel" implies that the ionic events can match the potential.

The marked inefficiency in removal of $\mathrm{Ca}$ from the liquid, as mentioned earlier, suggests either that few expansion paths for the cartridges got very close to the equilibrium path or that paths which approached it did not experience the degree of deposition indicated by the "deposition efficiency isopleths" of Figure 18. These latter isopleths are plotted as if deposition would respond instantly to the deposition potential; it is not assured that real processes will do so, though they may come close.

How significant the mismatch may be between the actual and potential deposition is indicated by the relative narrowness of some deposition zones indicated in Table 5 . Since some are only 2 or $3 \mathrm{~mm}$ wide, one can suspect that the actual deposition of $\mathrm{CaCO}_{3}$ does follow closely upon the development of its thermodynamic driving force. Thus, referring to the early part of the flashing where the initial delay was proposed as due jointly to (slow) ionic events following the delay in exhalation of $\mathrm{CO}_{2}$, one may suspect that the component of delay due to tardy losses of $\mathrm{CO}_{2}(\mathrm{aq})$ is the larger.

\section{Complete Pathways}

The trends of real expansion paths over the response surface maps can be plotted as in Figure 18. From the starting point, the paths plunge rather sharply away from the upper boundary but auickly bend toward it. The sharpness of this bend would be due to a high diffusion aradient for $\mathrm{CO}_{2}$ (aa) which could involve up to 1 atmosphere of pressure differential at $1 \%$ flash. Suhsequent loss of $\mathrm{CO}_{2}(\mathrm{aq})$ corresponds to the path's crossing the deposition efficiency isopleths at relatively high angles. It is this part of the path where $\mathrm{CaCO}_{3}$ deposition occurs. How far the path extends across the deposition efficiency isopleths depends jointly on: the fluid's residence time in those parts of the cartridge where deposition is thermodynamically possible; the diffusion gradient for the $\mathrm{CO}_{2}(\mathrm{aq})$ toward a free surface; and (presumably) the features of the pore structure which determine the values for mass flow rate, $\%$ flash, and fluid position. In a homogeneous matrix the segment of flow path in which deposition occurs is thin and near the exit 
face. By contrast, cartridges 8 and 18 , which acouired a sand cover that made a heterogenous matrix, had flashing near or upstream of their covers. This resulted in extending the segment of path for active deposition through most of the cartridge.

Just before the fluid exits the cartridge, the corresponding path on the response surface turns downward and its trend becomes essentially parallel to the Ca isopleths. This corresponds to a very rapid expansion in which the $\mathrm{CO}_{2}(\mathrm{aq})$ in the residual liquid probably enters the vapor phase without the enrichment expected for the counterpart equilibrium expansions. The fluid probably exited the cartridges at a temperature near $100^{\circ}$ and a $\mathrm{CO}_{2}$ pressure near $0.04 \mathrm{~kg} / \mathrm{cm}^{2}$. In these later stages of expansion, the $\mathrm{CO}_{2}$ diffusion gradient involves only a few hundredths of an atmosphere of differential. Thus, the $\mathrm{CO}_{2}(\mathrm{aq})$ molecules that are deeper beneath the vaporizing surfaces contribute relatively less to the flux of $\mathrm{H}_{2} \mathrm{O}$ plus $\mathrm{CO}_{2}$ leaving the surface than did their counterparts in earlier stages.

The course of the path below $100^{\circ} \mathrm{C}$ corresponds to the samples collected for $\mathrm{Ca}$ and $\mathrm{HCO}_{3}-/ \mathrm{CO}_{3}=$ analysis. These samples cooled, by conduction, toward the $25^{\circ} \mathrm{C}$ line. Since the liquid volumes were fairly massive and the pressures of $\mathrm{CO}_{2}(\mathrm{aq})$ within bottles were above that of the atmospheric $\mathrm{CO}_{2}$, precipitation of $\mathrm{CaCO}_{3}$ during short storage periods would not be expected. Note that a $\mathrm{CO}_{2}(\mathrm{aq})$ pressure of $0.01 \mathrm{~kg} / \mathrm{cm}^{2}$ corresponds to a head of only $100 \mathrm{~mm}$ of $\mathrm{H}_{2} \mathrm{O}$. Al though the $\mathrm{CO}_{2}$ at exit may be 30 times the atmospheric pressure, equilibration would be due to diffusion since $\mathrm{CO}_{2}$ bubbles can not form more than a few $\mathrm{cm}$ below the liquid surface. Energetics for nucleation of bubbles is a harrier for their development even at shallow depths.

Whether the initial course of the path will trend near the upper boundary of the expansion field or the lower one will depend on the relative rapidity of the expansion process. More rapid expansions will be further from the path for adabatic equilibrium.

Expansions that happen slower correspond to flow through channels -- fractures in rocks and in pipes. In addition to providing more time for the expansion, channels provide high turbulence which enhances the material transfer to the walls. Both of these features favor eauilibrium and such environments would have expansion paths that trend near the upper boundary.

Implications about Crystal Growth Mechanisms

Calcite is the first polymorph to deposit along the flowpath. Al though this may relate to its sliahtly smaller solubility compared to aragonite, it appears more likely that the cause lies in the crystal growth mechanisms. The fact that the liquid later reaches a condition where both calcite and aragonite grow means that calcite growth lags the thermodynamic buildup (i.e., becomes supersaturated) by an amount equal to or greater than the difference in formation energies for the two polymorphs. These differences are $0.084 \mathrm{kcal} / \mathrm{mole}$ at $150^{\circ}$ and $0.059 \mathrm{kcal}$ at $100^{\circ}$. By comparison, the driving force for calcite precipitation is 1.66 and $2.06 \mathrm{kcal} / \mathrm{mole}$ at the $1 \%$ and $2 \%$ flashing conditions, assuming no precipitation. Thus, it is not reasonable to use the difference in formation energies vis-a-vis calcite and aragonite to "explain" the presence of calcite.

Where the solution is. supersaturated in both polymorphs, the preponderance of aragonite would appear to be due to a more efficient use of available components compared to the calcite growth mechanism. This appears somewhat like a simple competition for scarce materials. However, the explanation more likely lies in the ways the $\mathrm{CO}_{3}=$ and $\mathrm{HCO}_{3}^{-}$participate in the buildup of the two crystal structures.

Clearly, aragonite has the faster growth mechanism as evidenced by its predominance at intermediate and late stages along the flow path. Yet, the $\mathrm{Ca}$ which both structures must utilize is only a little depleted in the fluids at those places. This suggests that absence of calcite may be due to unfavorable circumstances regarding the anions. It is noteworthy that in the earliest stages of flashing, Ca,ions are more abundant than $\mathrm{CO}_{3}$ ions. Later, $\mathrm{CO}_{3}$ ions are more abundant than Ca ions. Calcite forms in the first circumstance but not in the second, despite the presence of both an adequate thermodynamic drive and a reasonable supply of $\mathrm{Ca}$. Furthermore, at these intermediate stages, the $\mathrm{HCO}_{3}{ }^{-}$ concentration is not much changed from earlier. Thus one is led to suspect that $\mathrm{CO}_{3}$ ions, in overabundance, are detrimental to the caicite growth mechanism. One may conclude that the predominance of aragonite is due jointly to a growth mechanism that can readily utilize the buildup of $\mathrm{CO}_{3}=$ that accompanies flashing and to a suppression of calcite development by that same buildup. Similar conclusions have been reached el sewhere $(8,9)$.

A similar distribution pattern, calcite upstream of aragonite, occurs also in test loops used at East Mesa for other experiments. In these, geothermal water has been flashed in stages through orifice plates in large-diameter pipes ( 0.3 meter). Calcite forms in the upstream zones; aragonite is almost exclusive in the sections of lowest pressure/temperature. Significantly, single aragonite acicules from the bulk scale in the pipes are virtually indistinguishable from those found in the cartridges of this study.

\section{CONCLUSIONS}

An assortment of granular materials has provided permeable porous structures in which it was arranged for fresh geothermal 1 iquid to flash to steam. The flashing is well known to lead to the deposition of $\mathrm{CaCO}_{3}$. This study has dealt with specific facets of that deposition, especially the chemical aspects.

The deposition of $\mathrm{CaCO}_{3}$ ceased in most cases before the fluid exited the test substrates. The exit faces remained nearly free of deposits while the pores a few millimeters inward from the 
face were decorated substantially, sometimes enough to nearly block the fluid flow paths.

This experimental situation has a geologic counterpart where liquid productivity of the geothermal formations is too small to fill the bores of wells that tap it. Deposition of $\mathrm{CaCO}_{3}$ has been suspected in some circumstances like that. This study gives a basis for describing how the wells failed and what might be done to rejuvenate them.

By analogy, one can expect that $\mathrm{CaCO}_{3}$ will deposit in pore spaces beyond the well bore. How far into the reservoir rock this deposition may occur will depend on specifics about the pressure gradients, especially in the zone where 2-phase flow occurs. In these experiments the gross flow rate was controlled jointly by the circumstances in the 1-phase and 2-phase regions. In wells, one can expect that the 2-phase segment of the flow path will control flow rate and that segment will be shorter for rocks of lesser permeability. On this basis, one may conclude that damage to wells that produce through sandstone-like, permeability could be corrected by acid attack on the well bore to a depth of a few millimeters. It is important that for these cases the acid attack be limited to the near-surface material, intending to remove a small thickness without affecting the pore structure further in. New deposition would be made more efficient if the rocks were altered so that subsequent flow paths were from a less- to a more-permeable zone. This result is antipathetic to a common goal of acid treatment, namely, the partial consumption of matrix $\left(\mathrm{CaCO}_{3}\right)$ cement.

For cases where fluid enters the well bore through fractures, the $\mathrm{CaCO}_{3}$ deposition may extend far from the well bores. Wider fractures provide a longer path for the pressure drop during flow and hence a longer zone for $\mathrm{CaCO}_{3}$ deposition. Distances of centimeters to meters may become involved. Acid treatment for this case might not be successful if deposition had been allowed to become extensive enough to thoroughly block acid entry to the producing fractures. Making an effort to fracture the formation in conjunction with acid treatment might be attempted, but it is unlikely that original production could: be restored that way if multiple fractures were involved initially.

Fluids that are richer in $\mathrm{CO}_{2}$ are more sensitive to deposition in confined spaces. Partly, this is due to a higher $\mathrm{CO}_{2}$ pressure that enables the fluid to flash at smaller drawdowns of (bottom-hole) pressure. But more importantly, high- $\mathrm{CO}_{2}$ fluids are richer in $\mathrm{Ca}$, and a larger portion of that $\mathrm{Ca}$ is made thermodynamically ready to deposit (as $\mathrm{CaCO}_{3}$ ) for a given percent of flashing, compared to fluids that are poor in
$\mathrm{CO}_{2}$. This feature corresponds to paths on response surface maps that begin at a point far toward the right-hand side. Expansion from there will follow a pathway that trends near an equilibrium path, at least in the early stages. This results in prompt and severe supersaturation of $\mathrm{CaCO}_{3}$.

Detailed interpretation of results from the test cartridges reveals several features about the kinetics. Importantly, the deposition of $\mathrm{CaCO}_{3}$ lags the vaporization of $\mathrm{H}_{2} \mathrm{O}-\mathrm{CO}_{2}$ in the sense that the thermodynamic potential for deposition is always less than what an equilibrium calculation would show, sometimes subtantially less. The principal cause of this lag appears due to tardy exhalation of $\mathrm{CO}_{2}$ from the liquid, especially in later stages.

The consequences of non-equilibrium during flashing include inefficient removal of $\mathrm{Ca}$ from the liquid. Several experiments yielded only a $20 \%$ removal whereas equilibrium would be expected to achieve more than $90 \%$. Slower expansions for the flashing process favor a closer approach to equilibrium. Pipes and fractures in rocks would be expected to receive scale deposits at a higher chemical efficiency and over a much larger distance than would occur in porous materials.

Representation of the flashing process and of the non-equilibrium which attends it was done by using maps of response surfaces. Especially relevant is the map for Ca activity in the field of temperature and $\mathrm{CO}_{2}$ pressure within the liquid. An equilibrium pathway for the process can be calculated and plotted on the response surface. Several types of experimental data provide inferences about the real pathway at different stages and these permit sketching the real pathway onto the map alongside the calculated equilibrium path. The non-coincidence of the paths gives a graphic measure of non-equilibrium.

Construction of the response surface maps is based on the mathematics of carbonate equilibria. The formulation used in this description differed in two respects from common formulations. One of those accounts for the conversion of some bicarbonate to equal numbers of $\mathrm{CO}_{2}$ molecules and $\mathrm{CO}_{3}=$ ions during flashing, a feature often ignored. The other involved the combination of well-known equations for carbonate reactions into an equation that was independent of $\mathrm{pH}$. This eliminates the need to know, or to estimate, either the $\mathrm{pH}$ or the $\mathrm{CO}_{3}=/ \mathrm{HCO}_{3}$ - ratio in the fluid at reservoir conditions in order to calculate them at some other condition. This approach is especially relevant for alkaline geothermal waters that are charged with $\mathrm{CO}_{2}$, of which the fluid used in this experiment was one example. 
1. Truesdel1, A. H., Aquifer boiling may be normal in exploited high-temperature geothermal systems: 5th Workshop on Geothermal Reservoir Engineering, Stanford, Dec. 1979.

2. D. A. Campbel1, personal communcation

3. Pettijohn, F.J., 1957, Sedimentary rocks: Harper and Bros., New York, p. 59.

4. Bisque, R. E., 1961, Analysis of carbonate rocks for calcium, magnesium, iron, and aluminum with EDTA: Jour. Sed. Pet., v. 31, n. 1 , p. 113-122.

5. Gardner, W. E., 1979 X-ray diffration analysis of several samples for calcite/aragonite ratios: Technical Report 974021, Technology of Materials, Santa Barbara, Calif., 13 pp.

6. Saucier, R. J., 1974, Considerations in Gravel Pack Design: Petrol. Trans. v. 257, p. 205-212.

7. Hicks, C. R., 1964, Fundamental Concepts in the design of experiments: Holt, Rinehart and Winston, New York, p. $233-244$.

8. Heffner, J. D., 1976, Precipitation of metastable aragonite from aqeuous solution: Ph.D Thesis, U. of Penn., University Microfilms \#77-10,173, 152 pp.

9. Michels, D. E., in process, Nucleation of $\mathrm{CaCO}_{3}$ crystals on a non-carbonate substrate: Idaho National Engineering Laboratory, Idaho Falls.

\section{Mathematical Basis for Response Surface Maps}

Commonly, the set of galloping equilibria (A1 thru A5) is used, together with equations for charge and mass conservation, to describe carbonate reactions 1 . The set is solved simultaneously when the chemical equations are recast into a form that involves their equilibrium constants.

$$
\begin{aligned}
& \mathrm{CO}_{2}(\mathrm{~g})+\mathrm{H}_{2} \mathrm{O} \rightleftharpoons \mathrm{H}_{2} \mathrm{CO}_{3} \\
& \mathrm{H}_{2} \mathrm{CO}_{3} \rightleftharpoons \mathrm{H}^{+}+\mathrm{HCO}_{3}^{-} \\
& \mathrm{HCO}_{3}^{-} \rightleftharpoons \mathrm{H}+\mathrm{CO}_{3}^{=} \\
& \mathrm{Ca}^{++}+\mathrm{CO}_{3} \rightleftharpoons \mathrm{CaCO}_{3} \\
& \mathrm{H}^{+}+\mathrm{OH}^{-} \rightleftharpoons \mathrm{H}_{2} \mathrm{O}
\end{aligned}
$$

Two problems exist with this system of equations. A minor complication involves (A1) which commonly is used to describe the solubility of $\mathrm{CO}_{2}$ gas in water but is literally a hydrolysis reaction. The literal meaning of (A1) applies to only a very small part of the total carbonate in the East Mesa geothermal system because the $\mathrm{H}_{2} \mathrm{CO}_{3}$ is very scarce there (about $1 \mathrm{ppm}$ at reservoir conditions and near $.001 \mathrm{ppm}$ after flashing). The true dissolved form of $\mathrm{CO}_{2}$, described hereafter as $\mathrm{CO}_{2}(\mathrm{aq})$ is in fact a linear molecule not bonded to $\mathrm{H}_{2} \mathrm{O}$ much differently than, say, $\mathrm{N}_{2}$ is bonded to $\mathrm{H}_{2} \mathrm{O}$ when dissolved.

In contrast to the $\mathrm{CO}_{2} 1$ inear structure, the $\mathrm{H}_{2} \mathrm{CO}_{3}$ is trigonal-planar. Transitions from one structure to the other involve sluggish chemical reactions that are not part of the concept of gas solubility described by Henry's Law.

Thus, it is preferable to describe the solubility of $\mathrm{CO}_{2}$ by the simple equation,

$$
\mathrm{CO}_{2}(\mathrm{~g}) \rightleftharpoons \mathrm{CO}_{2}(\mathrm{aq})
$$

and recognize a direct proportionality between the partial pressure of the content of 1 inear $\mathrm{CO}_{2}$ molecules in the 1 iquid. This direct proportionality is one example of Henry's Law for dilute solutions. The constant of proportionality, Henry's constant, commonly is reported in units of partial pressure of $\mathrm{CO}_{2}$ per mole fraction of $\mathrm{CO}_{2}$ in the solution. More tractable units of $\mathrm{kg} / \mathrm{cm}^{2}$ per ppm are usable here because the $\mathrm{CO}_{2}(\mathrm{aq})$ is dilute in all circumstances.

Abandoning (AI) has the effect of requiring a separate accounting for the $\mathrm{CO}_{2}$ involved with Henry's Law, from $\mathrm{CO}_{2}$ derived through $\mathrm{HCO}_{3}^{-}$. There are two advantages in this. First, the $\mathrm{CO}_{2}$ which derives from $\mathrm{HCO}_{3}{ }^{-}$does not contribute

1e.g., Garrels, R.M., 1960, Mineral Equilibria:

Harper and Bros., New York, $254 \mathrm{pp}$. 
to the calculable pressure of $\mathrm{CO}_{2}$ that occurs in the 1-phase liquid before flashing, a fact which is not explicit with (A1). Second, the $\mathrm{CO}_{2}$ which does derive from the $\mathrm{HCO}_{3}$ - has important implications regarding the $\mathrm{CO}_{3}=/ \mathrm{HCO}_{3}{ }^{-}$ ratio which will be described later.

A major complication with (A2) and (A3) ${ }^{1}$ involves the $\mathrm{H}^{+}$, commonly represented by $\mathrm{pH}$. Significantly, $\mathrm{H}^{+}$is scarce in the East Mesa geothermal fluid since the liquid is alkaline under all degrees of flash; hence (A2) describes a non-process. Were the subject of this study to involve equilibrium conditions, then the use of (A2) would present no complication since the numerical relationships given by equilibrium constants are valid at equilibrium. But the emphasis here is on processes and on possible non-equilibrium situations. Thus it becomes appropriate to decline the traditional description of carbonate equilibria and seek a more realistic basis for calculations.

\section{Basis for Response Surface Maps}

The geothermal liquids at East Mesa are slightly alkaline under reservoir conditions and become more alkaline during normal flashing of steam and the concomitant depletion of $\mathrm{CO}_{2}(\mathrm{aq})$. Reaction (A7) describes the interconversion of three important species within this 1 iquid that are responsible for the $\mathrm{pH}$ behavior.

$$
2 \mathrm{HCO}_{3}{ }^{-} \rightleftharpoons \mathrm{CO}_{2}(\mathrm{~g})+\mathrm{H}_{2} \mathrm{O}+\mathrm{CO}_{3}=
$$

Under reservoir conditions $\mathrm{CO}_{3}=$ ions are scarce but they become abundant during flashing. Concomitantly, the $\mathrm{CO}_{2}$ produced according to (A7) enters the vapor pool that initially was (occupied only by $\mathrm{CO}_{2}(\mathrm{aq})$ ) dissolved according to Henry's Law. Thus; in terms of material remaining within the liquid phase, (A7) can be recast into (A8) which describes a mass balance for the liquid phase only.

$$
\mathrm{HCO}_{3}^{-}+2 \mathrm{CO}_{3}^{=}=\mathrm{M}
$$

The value $M$ closely represents the $\mathrm{HCO}_{3}{ }^{-}$concentration in the (pre-flash) reservoir fluid because at the temperature and $\mathrm{CO}_{2}$ pressure there the $\mathrm{CO}_{3}=$ is near zero. It is suspected that (A7) and (AB) describe actual processes during flashing and are thus important cornerstones of the mathematical. basis for the response surface maps.

The problem of assigning a pH to the mathematical model can be avoided by using relationship (A9) which is independent of $\mathrm{pH}^{2}$. The parentheses represent activities of the ionic species. Equation (A9) can be derived by combining those counterparts of $A 2$, $A 3$, and $A 6$ which include the equilibrium constants.

$$
\frac{\mathrm{PCO}_{2}\left(\mathrm{CO}_{3}^{=}\right)}{\left(\mathrm{HCO}_{3}^{-}\right)^{2}}=\frac{K^{\prime \prime}}{K^{\prime} \mathrm{h}}=A
$$

$\mathrm{PCO}_{2}=$ the Henry's Law pressure appropriate for the content of $\mathrm{CO}_{2}(\mathrm{aq})$ in the liquid,

$h=$ the Henry's Law constant in units of concentration per pressure,

$K^{\prime}=$ the dissociation constant for (A2) and

$K^{\prime \prime}=$ the dissociation constant for (A3).

The terms $h, K^{\prime}$, and $K^{\prime \prime}$ depend only on temperature. A selection of values is given in Table B1. Equations $A 8$ and $A 9$ can be solved simul taneously to yield $\mathrm{CO}_{3}=$ and $\mathrm{HCO}_{3}-$ activities, and their ratio defines pH through $\mathrm{A} 3$.

A) though (A9) can be derived al so from (Al), (A2), and (A3), and is thus mathematically consistent with them, those three equations are not arranged that way in other mathematical models of carbonate equilibria.. Other models do not involve the equality of $\mathrm{CO}_{2}$ and $\mathrm{CO}_{3}=$ that appears in (A7). This is a significant difference between the present development and other work and demonstrates that this development is more than a variant of other models. Note al so that the equality of $\mathrm{CO}_{2}$ and $\mathrm{CO}_{3}=$ in (A7) does not involve the Henry's Law- $\mathrm{CO}_{2}$ that is present initially.

The amounts of $\mathrm{CO}_{3}=$ and $\mathrm{HCO}_{3}-$ in the East Mesa fluid can overwhelm all other components there. Thus, the equilibrium concentrations of other ions can be calculated on the basis of these results and single chemical equations for other ions of interest. There is no need, in this circumstance, to solve more complicated sets of simultaneous equations.
1Usually, in solving Al-A5 et al. simultaneously, a pH is assigned in order to carry out the calculations. Such an assignment carries presumptions that are poorly justified, especially as regards A2. Al ternatively, some models involve an estimate of the $\mathrm{CO}_{3}=/ \mathrm{HCO}_{3}$ - ratio prior to "flash" and calculate a pH consistent with that ratio. Yet, guessing the $\mathrm{CO}_{3}=/ \mathrm{HCO}_{3}$ - ratio and calculating the $\mathrm{pH}$ is only a little more elegant than guessing the $\mathrm{pH}$ directly.

2 Smith, F.G., 1963, Physical geochemistry: Addison-Wesley, Paio Al to, p. 249. 


\section{APPENDIX B}

Construction of Response Surface Maps

Map for $\mathrm{CO}_{3} / \mathrm{HCO}_{3}$ Ratio

Equations (A9) and (A8) can be combined to yield ( $B 1$ ) which is convenient for constructing a response surface map of the $\mathrm{CO}_{3} / \mathrm{HCO}_{3}$ ratio. Subsequently, other maps for $\left(\mathrm{CO}_{3}=\right), \mathrm{pH},\left(\mathrm{Ca}^{++}\right)$, etc., can be made.

$\mathrm{PCO}_{2}=\frac{A M}{2\left[(\mathrm{R}+1 / 4)^{2}-1 / 16\right]}$

$\mathrm{R}$ is the activity ratio $\mathrm{CO}_{3} / \mathrm{HCO}_{3}$.

$M$ is the $\mathrm{HCO}_{3}$ - concentration in the reservoir

$A$ is given by equation

(A9)

The isopleth for a selected value of $R$ can be traced in a field of temperature and $\mathrm{CO}_{2}$ pressure (Figure $B I$ ) by entering (BI) with that R-value and sequentially using values for A selected from Table B1. The value for $M$ is uniform over all the map and $M=500 \mathrm{ppm}$ was used to construct Figures $B I$, BII and BIII.

It is worth noting here that activity coefficients have not been used in (B1). This leaves an inconsistency since $M$ involves concentrations and $R$, activities. The most obvious consequence is in reconciling the labels on the isopleths (which are activities) with analytical data on concentrations. For example, the two will differ in Figure BI by the factor $\gamma-2 / \gamma-1$, which has a value of 0.55 at $25^{\circ} \mathrm{C}\left(77^{\circ} \mathrm{F}\right)$. Different factors apply in other maps and at other temperatures. Maps could be constructed in units of concentration by using temperature-

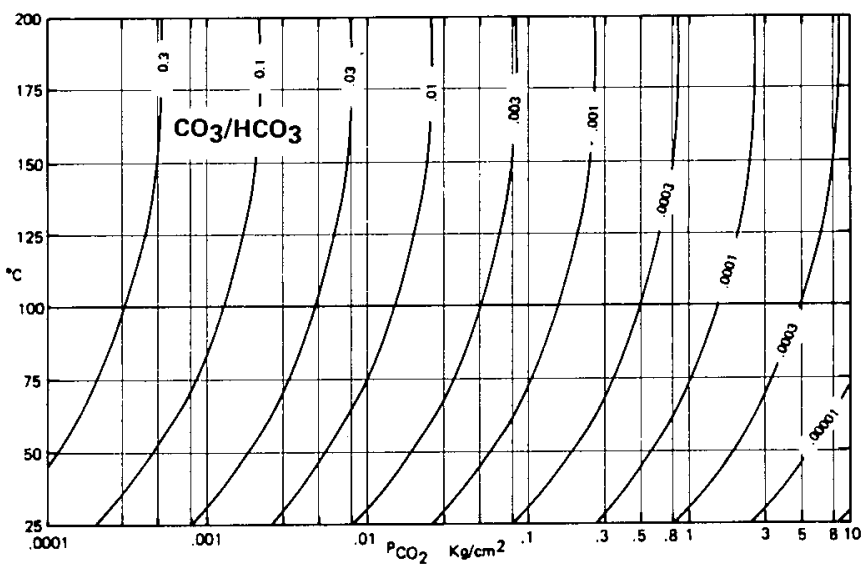

FIGURE BI: Response surface for $\mathrm{CO}_{3} / \mathrm{HCO}_{3}$ activity ratio in a field of Temperature and $\mathrm{CO}_{2}$ Pressure.

adjusted values for activity coefficients and applying them to $R$ for each calculation of $\mathrm{PCO}_{2}$. However calculated response surfaces which are uncompensated for the activity/ concentration aspect show the same local trends (topography) as would activity-compensated maps. This is because the compensation would result mainly in a shifting of the calculated surface up or down in space with only mild distortions resulting from different values of activity ratios that correspond to the temperature range across that space. Since it is the trends of response surfaces, not the absolute values, which are used el sewhere to describe the results of the $\mathrm{CaCO}_{3}$ deposition experiments, the mismatch between labels on the isopleths and analytical concentrations is not a serious matter.

Table B1: SELECTED DATA FOR CARBONATE EQUILIBRIA

\begin{tabular}{|c|c|c|c|c|c|c|c|c|c|}
\hline Temp ${ }^{\circ} \mathrm{C}$ & 25 & 50. & 75 & 100 & 125 & 150 & 200 & 250 & 300 \\
\hline $\log K^{\prime}(1)$ & -6.37 & -6.31 & -6.33 & -6.47 & -6.54 & -6.71 & -7.13 & -7.66 & -8.26 \\
\hline $\log K^{\prime \prime}(1)$ & -10.33 & -10.18 & -10.14 & -10.14 & -10.21 & -10.34 & -70.71 & -11.20 & -11.78 \\
\hline $\log k_{s p}$ (calcite) (1) & -8.36 & -8.61 & -8.96 & -9.38 & -9.84 & -10.34 & -11.40 & -12.51 & -13.63 \\
\hline $\log h(2,3)$ & -1.447 & -1.727 & -1.900 & -1.986 & -2.048 & -2.089 & -2.076 & -1.994 & -1.861 \\
\hline og $A(4)$ & -2.51 & -2.14 & -1.91 & -1.74 & -1.62 & -1.54 & -1.50 & -1.55 & -1.66 \\
\hline
\end{tabular}

1. From Kharaka, Y. F. and Barnes, Ivan, 1973, SOLMNEQ: Solution-mineral equilibrium computations: U.S. Geological Survey, NTIS PB - 215899, $82 \mathrm{pp}$.

2. Based on Ellis, A. J. and Golding, R. M., 1963, The solubility of carbon dioxide above $100{ }^{\circ} \mathrm{C}$ in water and in sodium chloride solutions: Amer. Jour. Sci., v. 261, pp 47-60.

3. Units are $\log$ (molal per $\left.\mathrm{kg} / \mathrm{cm}^{2}\right), \mathrm{CO}_{2}$ in water.

4. $A=\frac{K^{\prime \prime}}{K^{\prime} h}=\mathrm{kg} / \mathrm{cm}^{2}$ per molal 
Response Surface Map for $\mathrm{pH}$

The dissociation constant $K "$ for (A3) and the $\mathrm{CO}_{3}=/ \mathrm{HCO}_{3}-$ ratio define the $\mathrm{pH}$ as

in (B2) and (B3).

$$
\begin{aligned}
& \left(\mathrm{H}^{+}\right)=\mathrm{K}^{\prime \prime}\left(\mathrm{CO}_{3}{ }^{=} / \mathrm{HCO}_{3}{ }^{-}\right) \\
& \mathrm{pH}=-\log \left(\mathrm{H}^{+}\right)
\end{aligned}
$$

A response surface for $\mathrm{pH}$ (Fiqure $\mathrm{BII}$ ) can be constructed by tracing the $\mathrm{pH}$ isopleths across the field. A pH value is selected, a corresponding value of $\mathrm{CO}_{3}=/ \mathrm{HCO}_{3}$ - is calculated using (B2) and a value of $K^{\prime \prime}$ taken from Table $B 1$. Subsequently, that $\mathrm{CO}_{3}=/ \mathrm{HCO}_{3}{ }^{-}$can be entered into ( $\mathrm{B} 1$ ), along with a temperature-consistent value of $A$, to calculate the coordinate of $\mathrm{CO}_{2}$ pressure for the selected $\mathrm{pH}$.

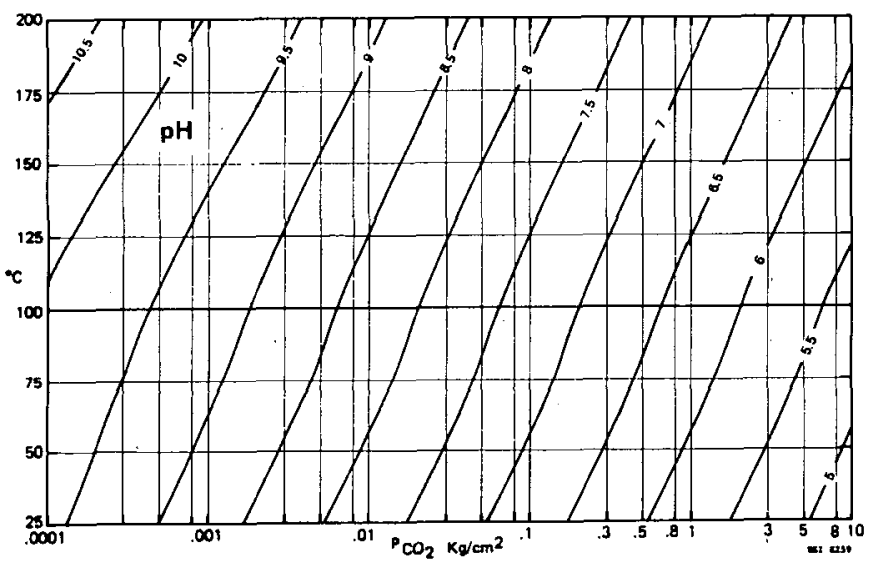

FIGURE BII: Response surface for $\mathrm{pH}$ in a field of Temperature and $\mathrm{CO}_{2}$ Pressure.

This method for calculating $\mathrm{pH}$ involves no arbitrary assumptions and no forcing of an ion charge balance from a fluid analysis. It is noteworthy that in this model, $\mathrm{pH}$ is a dependent variable determined by the partitioning of material in the $\mathrm{CO}_{3}=$ and $\mathrm{HCO}_{3}{ }^{-}$compartments of the system. In terms of actual abundance, $\mathrm{H}^{+}$always is a trace component. Its calculated value, as obtained here, is determined by the concentrations of major components in the system.

Response Surface Map for Ca

Because $\mathrm{HCO}_{3}^{-}(500 \mathrm{ppm})$ is so much more available in East Mesa fluid than Ca (6.3ppm), calculations regarding the precipitation of $\mathrm{CaCO}_{3}$ can ignore depletion of the $\mathrm{HCO}_{3}^{-}-\mathrm{CO}_{3}=$ couple. Even under conditions where the actual concentrations of $\mathrm{CO}_{3}=$ are small, losses due to formation of $\mathrm{CaCO}_{3}$ can be made up from the $\mathrm{HCO}_{3}^{-}$ supply in accordance with (A7). Consequently, the equilibrium concentration of $\mathrm{Ca}$ can be connected in a simple way to (B1) through equations $B 4$ and (AB).

$$
\left(\mathrm{Ca}^{++}\right)=\frac{\hat{K}_{\mathrm{sp}}}{\left(\mathrm{CO}_{3}{ }^{=}\right)}
$$

The procedure for tracing the $\mathrm{Ca}$ isopleths is similar to that used for $\mathrm{pH}$. A value of $\mathrm{Ca}$ is selected and used with a value of $\mathrm{Ksp}$ from
Table $\mathrm{B} 1$ to yield a value for $\mathrm{CO}_{3}=$ based on (B4). That $\mathrm{CO}_{3}=$ value is used in (A8) to find a value for $R$ which is applied in (B1) to find the $\mathrm{PCO}_{2}$ coordinate for the selected Ca value. The result is Figure BIII.

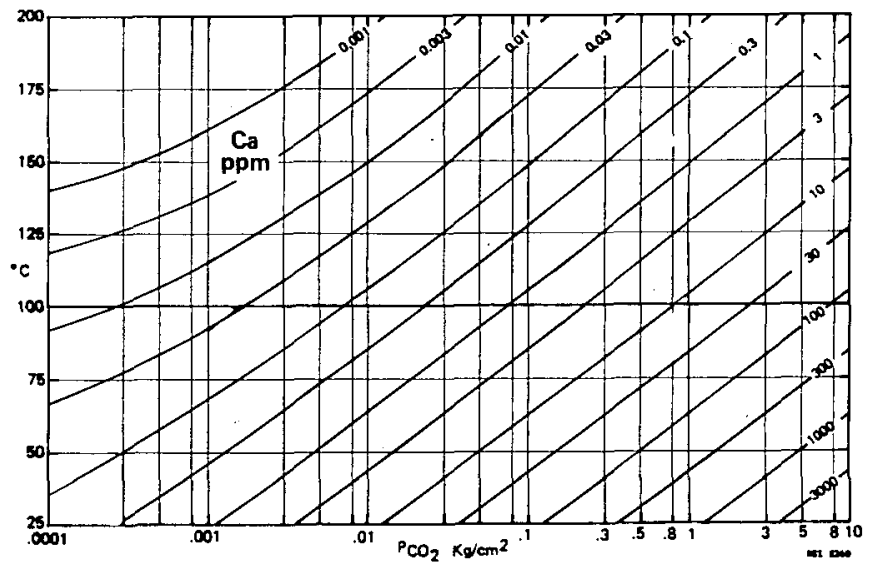

FIGURE BIII: Response surface for Ca activity in a field of Temperature and $\mathrm{CO}_{2}$ Pressure.

Because activity coefficients were not used, the numerical labels on the calculated $\mathrm{Ca}$ isopleths differ from analytical data by about a factor of 10. However, the trends of the surface and the slopes (spacings of the isopleths) are in proper order and can be used to describe events that occur in the flashing process.

The spacings of the Ca isopleths is logarithmic in the Temp-Pressure field, demonstrating that the Ca concentration is basically proportional to $\mathrm{CO}_{2}$ pressure. This outcome contrasts to some published relationships which show that the $\mathrm{Ca}$ concentration is approximately proportioned to the cube root of the $\mathrm{CO}_{2}$ pressure. 2 Those latter relationships are based on a process where in $\mathrm{HCO}_{3}^{-}$and $\mathrm{Ca}^{++}$ ions jointly are the dominant ionic species and are:present in the proportion of $2: 1$; as in the context of calcite dissolving in water in contact with a source of $\mathrm{CO}_{2}(\mathrm{~g})$. Because the geothermal case is far from a 2:1 proportion for $\mathrm{HCO}_{3}: \mathrm{Ca}$, the cube root relationship is not obtained.

\footnotetext{
${ }^{1}$ Such refinements should recognize al so the formation of species like $\mathrm{NaCO}_{3}^{-}$and $\mathrm{CaCO}_{3}{ }^{\circ}$ which also affect the $\mathrm{R}$ values et al. These refinements can be done by computer. The simpler maps presented here can be developed with desk calculators.
}

2Holland, H.D., 1978, The chemistry of the atmosphere and oceans: John Wiley \& Sons, New York, n. 18, 


\section{APPENDIX C}

Equilibrium Paths Across Response Surfaces and Definition of Non-Equilibrium

The temperature and $\mathrm{CO}_{2}$ pressure in the geothermal fluid, before it entered the experimental cartridges, can be represented by a point on the response surface maps. The actual content of $\mathrm{CO}_{2}(\mathrm{aa})$ involved with the experimental well 56-30 varies from 300 to $500 \mathrm{ppm}$ on a total fluid basis and can be considered as nominally 400 $\mathrm{ppm}$. This corresponds to a Henry's Law pressure of about $1.13 \mathrm{~kg} / \mathrm{cm}^{2}$ at $158^{\circ}$. Those coordinates describe the starting point for all flashing processes that the experimental fluid may undergo.

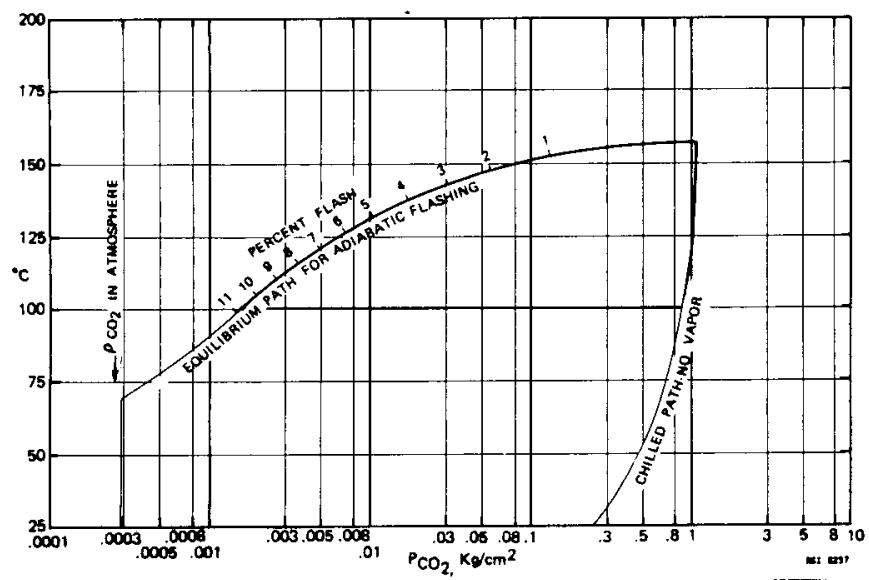

FIGURE C1: Pathway Diagram for depressuring the geothermal liquid from E.M. well 56-30. Pathways lying below the equilibrium adiabatic path are possible. These may also be adiabatic, but they involve non-equilibrium regarding the $\mathrm{CO}_{2}$ distribution between liquid and vapor.

Similarly, the coordinate $\left(100^{\circ}, 0.00028\right.$ $\mathrm{ka} / \mathrm{cm}^{2}$ ) is a point which represents (the surface of) freshly flashed liquid exposed to the atmosphere. A line connecting the two points will describe the continuous Temperature- $\mathrm{CO}_{2}$ relationship during the flashing process.

The traces of several paths can be calculated and plotted. Of special utility is the calculated path for an adiabatic expansion in which chemical equilibrium between the vapor and the liquid is maintained. The $\mathrm{CO}_{2}(\mathrm{~g})$ pressure in the vapor during such an expansion can be estimated to a good order by the following procedure and then plotted in the response surface maps.

For the liquid, (C1) shows the Henry's Law relationship.

$$
\mathrm{PCO}_{2}=\mathrm{CO}_{2 \mathrm{~L}}(\mathrm{~h})
$$

$\mathrm{CO}_{2 L}$ represents the residual $\mathrm{CO}_{2}(\mathrm{aq})$ at any point during the flashing.

For the vapor, the total pressure is partitioned as in (C2).

$$
{ }^{\mathrm{PCO}_{2}}=\mathrm{P}_{\mathrm{T}} \text { (mole fraction) }
$$

for which the total pressure is given approximately by (C3) (ignoring other gases).

$$
P_{T}=P_{\mathrm{H}_{2} \mathrm{O}}+P_{\mathrm{CO}_{2}}
$$

The mole fraction in the vapor is given by (C4).

$$
\text { mole fraction }=\frac{\left[\mathrm{CO}_{2 R}-\mathrm{CO}_{2 L}\right](\mathrm{a})}{\mathrm{f}}
$$

in which

$\mathrm{CO}_{2 \mathrm{R}}$ is the content of $\mathrm{CO}_{2}(\mathrm{aq})$ in the liquid before flash.

$f$ is the mass fraction of the $\mathrm{H}_{2} \mathrm{O}$ which has vaporized, and

(a) is a conversion factor with units of concentration/mole fraction.

(C1) through (C4) yield a quadratic equation for $\mathrm{PCO}_{2}$. It is solved by taking the $(+)$ sign only for the square root term, as in (C5).

$$
\mathrm{PCO}_{2}=1 / 2\left[\left(\mathrm{~J}^{2}+4 \mathrm{P}_{\mathrm{H}_{2}} \mathrm{O} h \mathrm{hCO}_{2 \mathrm{R}}\right)^{1 / 2}-\mathrm{J}\right]
$$

The term $\mathrm{J}$ depends only on temperature.

$$
\mathrm{J}=\frac{\mathrm{hf}}{\mathrm{a}}+\mathrm{P}_{\mathrm{H}_{2}} \mathrm{O}-\mathrm{hCO} 2 \mathrm{R}
$$

The locus of points given by $\mathrm{C5}$ is the equilibrium path and its position in the response surface maps marks the upper boundary of all possible paths for flashing from reservoir conditions.

The lower boundary for the region of possible paths corresponds to no loss of $\mathrm{CO}_{2}$ by the liquid during cooling and can be found by using (C1) and (C7) for the whole process.

$$
\mathrm{CO}_{2 \mathrm{~L}}=\mathrm{CO}_{2 \mathrm{R}}
$$

When geothermal liquid begins to flash, the first vapors to form are relatively rich in $\mathrm{CO}_{2}$ compared to the residual 1 iquid. As flashing progresses, the vapors which form later are less rich in $\mathrm{CO}_{2}$ than those formed earlier.

In the East Mesa case the first vapors to form are about 85 mole percent $\mathrm{H}_{2} \mathrm{O}$ which corresponds to the coordinate point $(1.13$ $\mathrm{kg} / \mathrm{cm}^{2}$ of $\left.\mathrm{CO}_{2}, 158^{\circ}\right)$. The $\mathrm{H}_{2} \mathrm{O}$ vapor pressure at $158^{\circ}$ is $5.87 \mathrm{~kg} / \mathrm{cm}^{2}$ abs. Those two pressures are the major contributors to the flash pressure, others are $\mathrm{N}_{2}, \mathrm{CH}_{4}$, et al.

The $\mathrm{CO}_{2}$ derived from $\mathrm{HCO}_{3}^{-}$, as in (A7), contributes to the $\mathrm{CO}_{2}(\mathrm{~g})$ pressure only minorly. Ultimately, 20 to $60 \mathrm{ppm}$ of $\mathrm{CO}_{2}$ (total fluid basis) via (A7) will join the 300 to $500 \mathrm{ppm}$ of $\mathrm{CO}_{2}$ (total fluid basis) present before flashing. The latter range of values is the observed variation over historical production. One may argue that since the $\mathrm{CO}_{2}$ pressure changes by a factor of about 1000 during flashing, the fact that 10 to 20 percent of the $\mathrm{CO}_{2}$ is newly generated has a negligible effect on the overall composition of the vapor. Such a view is 
appropriate to events in the vapor phase and is consistent with the simple way of calculating the $\mathrm{CO}_{2}$ pressure used above.

\section{A Definition of Non-Equilibrium}

It is intended here, when considering the. 1 iquid phase, to visualize a $\mathrm{CO}_{2}$ pressure within it of a magnitude given by the Henry.'s Law constant times the concentration of $\mathrm{CO}_{2}(\mathrm{aq})$, irrespective of whether the partial pressure of $\mathrm{CO}_{2}$ in the nearby vapor phase is of similar magnitude. Such a view yields one measure of non-equilibrium, namely, the inequality of the actual $\mathrm{CO}_{2}$ pressure in the vapor compared to the (calculable) Henry's Law pressure in adjacent liquid. Non-equilibrium in the liquid is promoted by those factors which delay or obstruct the movement of $\mathrm{CO}_{2}(\mathrm{aq})$ into the vapor phase.

This definition incorporates two separate aspects of the quickly changing conditions observed when "following" an increment of liquid along the flashing path: 1) The conditions of chemical equilibria in the liquid are shifting, always in the same directions toward an equilibrium "target" at al1 instants of time; and 2) the "target" shifts continuously during the process. The non-equilibrium is a kind of chemical distance between the target and the actual conditions. Its magnitude depends jointly on those two kinds of shifting. 
This report was done with support from the Department of Energy. Any conclusions or opinions expressed in this report represent solely those of the author(s) and not necessarily those of The Regents of the University of California, the Lawrence Berkeley Laboratory or the Department of Energy.

Reference to a company or product name does not imply approval or recommendation of the product by the University of California or the U.S. Department of Energy to the exclusion of others that may be suitable. 
TECHNICAL INFORMATION DEPARTMENT

LAWRENCE BERKELEY LABORATORY

UNIVERSITY OF CALIFORNIA

BERKELEY, CALIFORNIA 94720 